\title{
Defining optimal configurations of geothermal systems using process design and process integration techniques
}

\author{
Laboratory for Industrial Energy Systems, Ecole Polytechnique Fédérale de Lausanne \\ $\mathrm{CH}$ - 1015 Lausanne, Switzerland \\ Léda Gerber, François Maréchal
}

Accepted by Applied Thermal Engineering on 17.11.2011

\begin{abstract}
This paper presents a systematic methodology for the optimal design of geothermal systems. First, the different components of the system superstructure are separately modeled using flowsheeting software. The superstructure includes the different conversion technologies, the potential resources and the demand profiles in energy services. It covers a wide pannel of conventional resources and technologies like deep and shallow aquifers, heat pumps, organic Rankine cycles for combined heat and power production, as well as emerging resources and technologies, like Enhanced Geothermal Systems. Then, resources, technologies and demand profiles models are integrated together using process integration techniques. The configuration of the geothermal system is hence extracted from the superstructure. Finally, the performance of the integrated system is calculated and includes energy and exergy efficiency, investment costs, operating costs and district heating or electricity levelized costs. To account for the seasonal variations of the demand, a multi-period approach is used for the simulation of the superstructure, its integration and the performance calculation. The overall sequence is implemented in a multi-objective optimization framework. The methodology is illustrated by an application case study. The implications of the results are discussed in terms of important effects to be accounted for in the design of geothermal systems.
\end{abstract}

\section{Introduction}

In the perspective of increasing the share of renewable energy to mitigate global warming issues and to respond to fossil resources depletion, the use of geothermal energy has gained interest. Major usages of geothermal energy include electricity production (67246 GWh/y in 2010) and direct use for heating (117740 GWh/y in 2010) (1). As stated by the International Energy Agency (IEA) in its roadmap for geothermal energy (2), by 2050 the geothermal power production should be increased to $1400 \mathrm{TWh} / \mathrm{y}$, and the direct use to $1600 \mathrm{TWh} / \mathrm{y}$. These objectives are expected to be reached by developing both conventional resources like hydrothermal aquifers and emerging ones like Enhanced Geothermal Systems (EGS). Hence, geothermal heat and power production are expected to know an important development in the future.

However, its economic competitiveness is still a critical point (2). While the drilling of wells dominate the repartition of the investment costs, already proposed strategies for increasing costeffectiveness pay all major attention to the design of the conversion system. In this optic, Desideri and Bidini (3) state the bases of a methodology to select and design cycles for power generation from low-temperature geothermal resources, for flash systems, organic Rankine cycles (ORC) and Kalina cycles. Later, several studies extended this method specifically for ORCs, including many potential working fluids $(4 ; 5 ; 6 ; 7 ; 8)$. Similar approaches were developed for the design of advanced conversion cycles, such as supercritical cycles (9) or fluid mixtures (10). Recently, Lazzaretto et. al. (11) demonstrated the validity of the thermo-economic optimization approach to design geothermal power plants. 
While the above studies focus on electricity production, other ones show the attractiveness of geothermal combined heat and power (CHP) production. Kanoglu et. al. (12) demonstrated the advantages of incorporating district heating and cooling systems in existing geothermal power plants. Later, Heberle and Brüggemann $(13)$ and Guo et al. $(14 ; 15)$ extended the approach for the selection of working fluids in ORCs including CHP possibilities. Guo et al. $(14 ; 15)$ discuss the influence of district heating parameters, but do not conduct a systematic optimization including all the decision variables, neither account for the seasonal variations of the district heating demand.

The performance assessment in the above studies includes generally both economic and thermodynamic criteria, exergy efficiency being the most appropriated indicator for this last aspect, according to DiPippo (16). Furthermore, Coskun et al. (17) and Kanoglu and Dincer (18) have shown the suitability of exergy analysis to assess the different components of geothermal power and CHP plants, respectively. Ozgener et al. (19;20) integrated the characteristics of the geothermal resources and district heating in the performance evaluation. The integration of site-specific data is also realized in a recent study by Beck et al. (21), applying optimization techniques for maximizing the energy extraction of a shallow geothermal system.

Furthermore, process design and process integration, initially used in the field of industrial processes $(22 ; 23 ; 24 ; 25 ; 26)$, have proven to be suited for the conceptual design of renewable energy conversion systems $(27 ; 28 ; 29 ; 30 ; 31)$, but have not yet been applied to the design of geothermal systems.

The development of a systematic methodology integrating all the aspects treated in the above studies (i.e. conversion technology models, district heating demand parameters, geothermal resources characteristics) in combination with process integration and multi-objective optimization (MOO) techniques has not been realized yet and would allow to identify the optimal configurations of geothermal energy conversion systems for geo-localized conditions. The bases of such an approach have been already presented in (32). It was however not demonstrated by a detailed application and MOO was not performed to systematically calculate the optimal configurations. This paper aims at extending this method, and presents an application case study for which the overall geothermal system is designed, including resources, technologies and district heating.

\section{Methodology}

Geothermal system design aims at defining, for a given geographical location, the geothermal depth and flow, the configuration in terms of equipment sizes and operating conditions of the conversion system, as well as the operation strategy to supply the energy services of the area. It is a multi-period problem that accounts for seasonal variations of the demand. Due to the geological uncertainties, the present methodology is applicable only to orientate the decisionmaking and the future development of geothermal energy on a given area for which the geology is known and the demand in energy services characterized. Moreover, it applies to systems that can be operated in independent time intervals (i.e. without seasonal heat storage). It is used for preliminary design, leading to promising configurations for which a detailed system engineering like in (11) is still to be done.

The general computational framework creates interfaces between different models and is described in Figure 1.Considering that both the operating conditions and the equipment sizes are optimized, the problem is by essence a mixed integer non linear (MINLP) programming problem. In addition, as the heat cascade is used to model the heat transfer together with the optimization of the temperature levels, the problem is non differentiable. Therefore, a two-step optimization strategy is used, with a decomposition in a slave Mixed Integer Linear Programming (MILP) subproblem solved independently for each period and in a master non-linear problem solved for the overall yearly operation of the system. A dedicated MINLP optimization algorithm is thus needed. The method is described in (33). A superstructure including the optional 


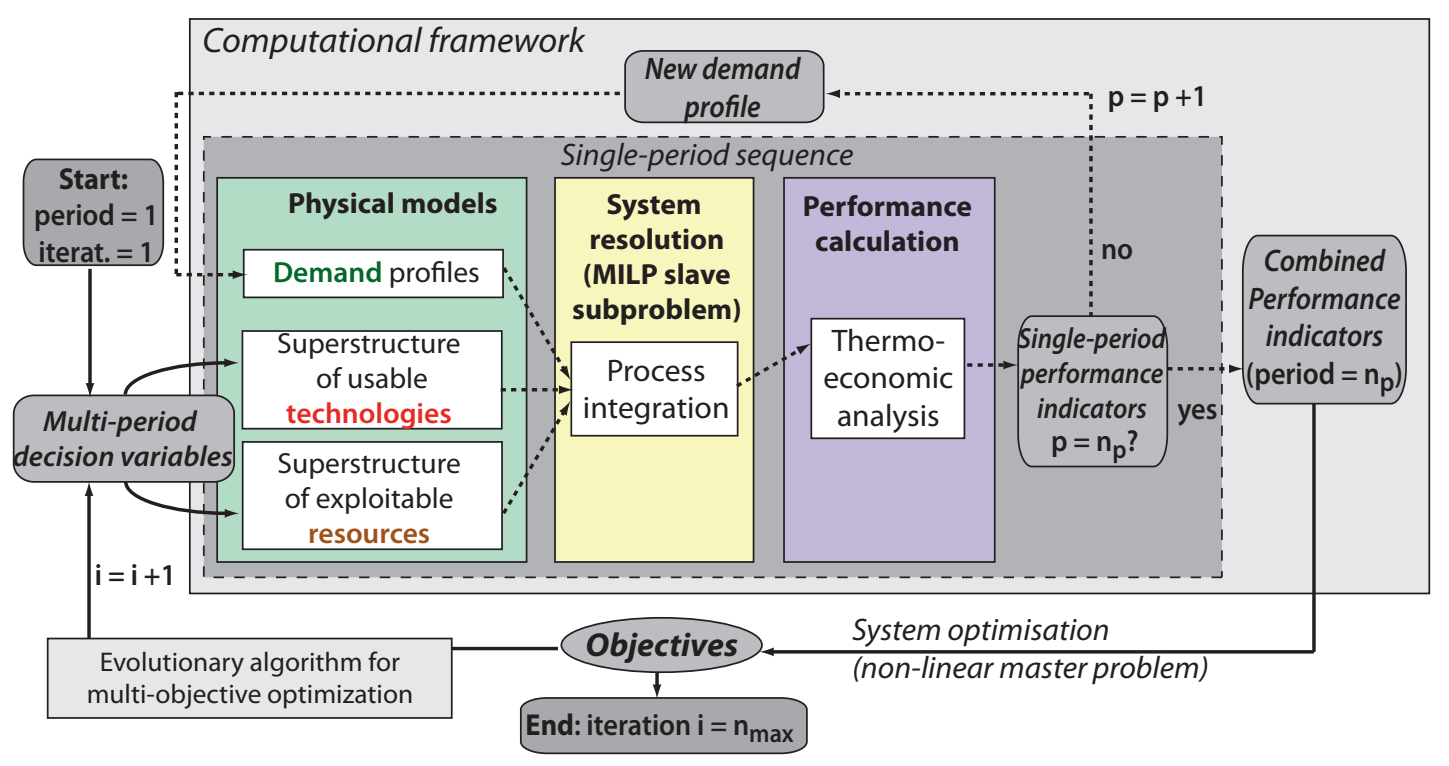

Figure 1: Computational framework

technological solutions and the potential resources is built and the thermo-economic models of these components are developed. First the three different sub-systems composing a geothermal system are simulated separately. These include:

1. the potential geothermal resources from which heat can be harvested

2. the potential conversion technologies

3. the geolocalized demand profiles in energy services

Each model of a resource or a technology included in the superstructure and of the seasonal demand in energy services is thus simulated for a given set of operating conditions (period $=1 \ldots n_{p}$ ). This allows one to operate the system in function of the seasonal variation of the energy service requirement. These sub-systems are then integrated together using process integration techniques to build the overall system to supply energy services, solving the slave MILP subproblem, which decision variables are the utilization rates of the different resources and technologies of the superstructure simulated at the previous step. At the end of the single-period sequence, thermoeconomic performances of the integrated system are calculated. The whole sequence is repeated for each period (until period $=n_{p}$ ). Then, overall performance indicators are calculated for the yearly operation of the system by combining the seasonal performance indicators. It includes the objective functions of the MOO master problem, solved using an evolutionary algorithm (34). The sequence with the $n_{p}$ periods is repeated for $n_{\max }$ iterations to complete the MOO, with different values for decision variables at each iteration, which relate to:

1. the definition of the configuration extracted from the superstructure using integer variables (i.e. if a particular resource/technology is used or not)

2. the system operating conditions (temperatures, pressures)

3. the depth and size of the geothermal resource harvesting system (well size, flow and coverage)

Each step of the computational framework and its application to the case study is detailed in the sections below. 


\subsection{Geothermal system model}

\subsubsection{Geothermal resources model}

A database contains the superstructure of geothermal resources. These are defined by the depth, the harvesting technique and the potential of the geological layers to be exploited for geothermal applications. They include: shallow aquifers (SA), going from the surface down to a few hundred meters, deep aquifers (DA), from a few hundreds meters down to the bedrock, and Hot Dry Rock (HDR), below the limit of the bedrock where an EGS can be built. Conceptual flowsheets for the models of the aquifers and of the EGS are available in Appendix A, in Figures 10 and 11. A resource model contain three important parameters to calculate its expected thermal power, exergy available, and associated cost:

1. the depth $z$, in $\mathrm{m}$

2. the temperature $T_{r, z}$, in ${ }^{\circ} \mathrm{C}$

3. the expected mass flow rate $\dot{m}$, in $\mathrm{kg} / \mathrm{s}$

The applicability of the method involves that geological surveys have been performed in the area to assess the potential resources. Though the potential aquifers with their associated depths and temperatures are usually identified by such surveys $(35 ; 36)$, the mass flow rate is not known before drilling and testing, and only an expected range is given. The model of EGS assumes a mature commercial technology, expected to be achieved in the next decades (37).

For the case study, the definition of the exploitable aquifers is based on the work of (38), which consists in a simplified tridimensional model for the identification of the potential exploitable geothermal resources in Western Switzerland, from the surface down to $3000 \mathrm{~m}$. The domain of validity for an EGS corresponds to the limit of the bedrock, around 3000m in Switzerland, down to $10000 \mathrm{~m}$, which represents the accessible resource with the present drilling technology (37).

Details of the calculations for the temperatures, thermal powers and costs, as well as assumptions and data taken for the case study are in Appendix A.

Table 1 shows the superstructure of resources extracted from the database for the case study.

\begin{tabular}{|c|c|c|c|c|c|c|}
\hline $\begin{array}{l}\text { Abbre- } \\
\text { viation }\end{array}$ & Resource type & $\begin{array}{l}\text { Depth, } \\
\text { in } m\end{array}$ & $\begin{array}{l}\text { Expected } \\
\text { tem- } \\
\text { pera- } \\
\text { ture, in } \\
{ }^{\circ} C\end{array}$ & $\begin{array}{l}\text { Expected } \\
\text { mass } \\
\text { flow } \\
\text { rate, in } \\
L / s\end{array}$ & $\begin{array}{l}\text { Numbe } \\
\text { of } \\
\text { wells }\end{array}$ & $\begin{array}{l}\text { Carnot } \\
\text { factor }^{a}\end{array}$ \\
\hline SA-30 & Shallow aquifer & 30 & 12 & 20 & 2 & 0.007 \\
\hline SA-150 & Shallow aquifer & 150 & 16 & 20 & 2 & 0.021 \\
\hline SA-600 & Shallow aquifer & $300-600$ & $20-30$ & 20 & 2 & $\begin{array}{l}0.034- \\
0.021\end{array}$ \\
\hline DA-1300 & Deep aquifer & $1100-1300$ & $50-57$ & 20 & 2 & $\begin{array}{l}0.124- \\
0.142\end{array}$ \\
\hline DA-2500 & Deep aquifer & 2500 & 98 & 20 & 2 & 0.237 \\
\hline EGS & Hot Dry Rock & $\begin{array}{l}3000- \\
10000\end{array}$ & $104-370$ & 50 & 3 & $\begin{array}{l}0.249- \\
0.560\end{array}$ \\
\hline
\end{tabular}

${ }^{\text {a }}$ calculated using a cold source at $10^{\circ} \mathrm{C}$, assumed to be a river

Table 1: Characteristics of the potential resources for the application case study

\subsubsection{Conversion technologies}

The superstructure of conversion technologies includes different CHP cycles (flash systems and ORCs (39)), heat pumps, and back-up systems. In single- and double-flash systems, the liquid 
remaining part after flashing is used for heat supply before reinjection. ORCs include different working fluids and two designs: single-loop and with an intermediate draw-off from the turbine to supply high-temperature heat. The flowsheeting software Belsim-Vali (40) is used to simulate the operating conditions and to calculate the corresponding thermodynamic states of each technology. The mass flow rates and the thermal and electrical powers are computed from these data for the system integration and sizing.

The conceptual flowsheets of the technologies and the thermodynamic data of the working fluids are in Appendix B, in Figures 12 to 16, and in Table 6.

The summary of the conversion technologies used for the case study is in Table 2. Only the ORCs models using isobutane have been chosen, since this working fluid is used for the EGS application of Soultz-sous-Forêts (41). All the cycles for electricity production have cogeneration

\begin{tabular}{|c|c|c|}
\hline Abbreviation & Technology & Varying parameters \\
\hline $1 \mathrm{~F}$ & Single-flash system & flash-drum pressure \\
\hline $2 \mathrm{~F}$ & Double-flash system & 1st and 2nd flash-drum pressures \\
\hline ORC-s & $\begin{array}{l}\text { ORC with single-loop, using } \\
\text { isobutane }\end{array}$ & $\begin{array}{l}\text { evaporation temperature, super- } \\
\text { heating temperature }\end{array}$ \\
\hline ORC-d & $\begin{array}{l}\text { ORC with intermediate } \\
\text { draw-off, using isobutane }\end{array}$ & $\begin{array}{l}\text { evaporation temperature, super- } \\
\text { heating temperature, splitting frac- } \\
\text { tion for draw-off, condensation tem- } \\
\text { perature for draw-off }\end{array}$ \\
\hline HP & Heat pump, using R134a & $\begin{array}{l}\text { evaporation temperature, conden- } \\
\text { sation temperature, subcooling } \\
\text { temperature }\end{array}$ \\
\hline boiler & $\begin{array}{l}\text { boiler using natural gas, } \\
\text { used as a back-up system }\end{array}$ & \\
\hline
\end{tabular}

Table 2: Characteristics of the conversion technologies for the case study

in parallel (flash systems and single-loop ORC) or in the cycle (ORC with draw-off). The cold source is a river at $10^{\circ} \mathrm{C}$, representative of the average conditions of Switzerland.

\subsubsection{Energy services demand profiles}

In order to represent the seasonal variations of the demand in energy services (i.e. district heating and hot water), the yearly operation is divided in 4 periods corresponding to a different average ambient temperature for the corresponding period duration. For each period and each building, a building model is used to calculate the temperature-enthalpy profile of the heat demand. The demands are then aggregated to form a demand Grand composite curve, following the methodology of Girardin et. al. (42).

Figure 2 presents 4 corresponding composite curves calculated for a residential area of the city of Nyon, located in the Swiss Plateau, with a built surface of $177000 \mathrm{~m}^{2}$ and a total demand of $9153 \mathrm{MWh} / \mathrm{y}$ in district heating and domestic hot water. The operating time associated with each period is as well indicated. This example is used for the appplication case study. The composites presented in Figure 2 concern a complete area. Therefore it includes on the same graph heat demands for buildings differing by age, quality and usage, as well as the hot water production.

\subsection{Process integration}

Resources, technologies and demand profiles are integrated using process integration techniques $(22 ; 24)$. A MILP problem is solved to minimize the operating cost of the system for each single period. Indeed, with the two-step decomposition of the optimization, the non-linear investment 


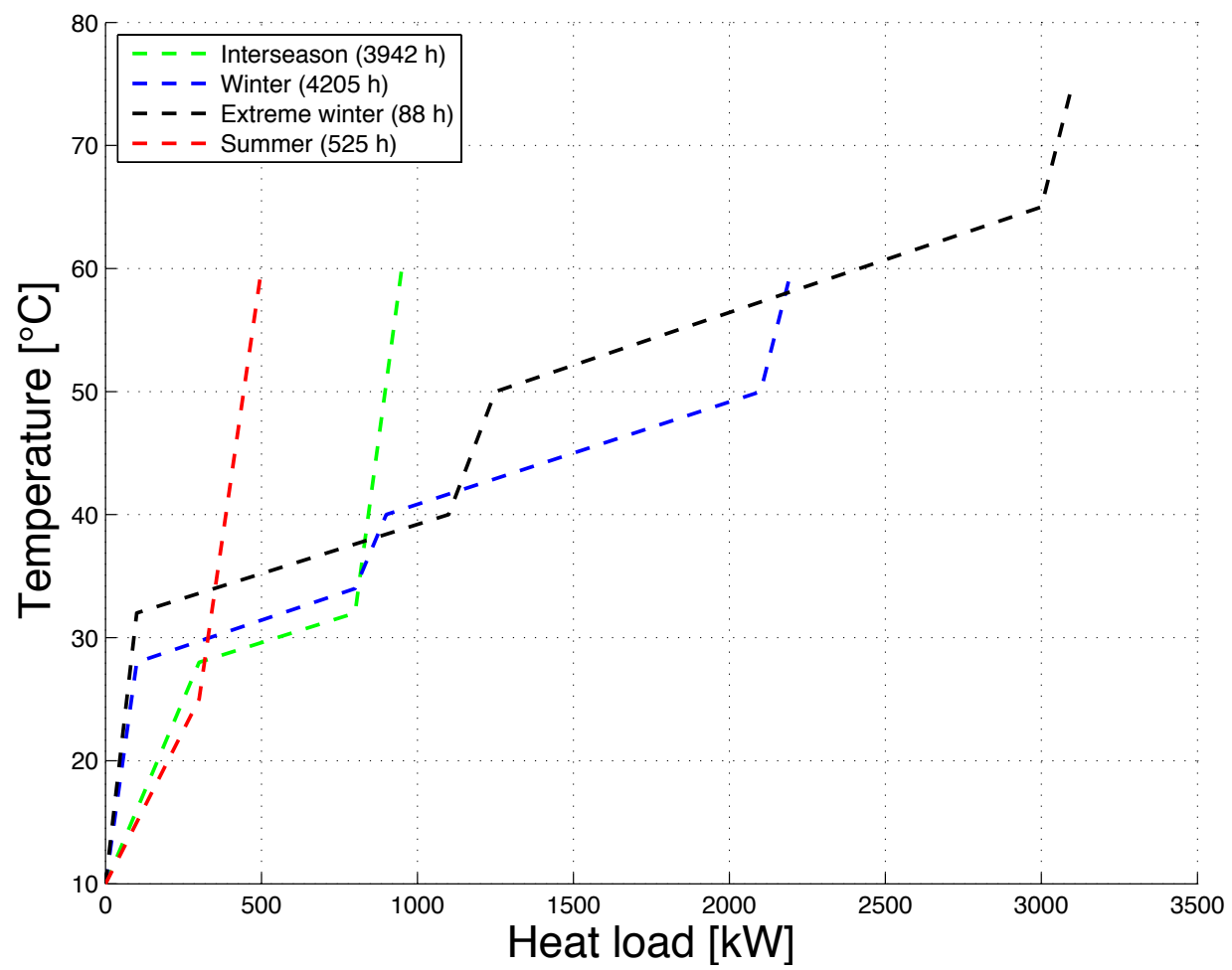

Figure 2: Seasonal demand profiles in space heating and hot water for the case study

cost of the system is realized by the master problem.

$$
\min \left(\sum_{r=1}^{n_{r}}\left(C_{O_{r}}\left(x_{d}\right) \cdot \mathbf{f}_{\mathbf{r}}\right)+\sum_{w=1}^{n_{w}}\left(C_{O_{w}}\left(x_{d}\right) \cdot \mathbf{f}_{\mathbf{w}}\right)+c_{e}^{+} \dot{\mathbf{E}}_{\text {grid }}^{+}\left(x_{d}\right)-c_{e}^{-} \dot{\mathbf{E}}_{\text {grid }}^{-}\left(x_{d}\right)\right)
$$

where $C_{O_{r}}$ is the operating cost of the resource $r$ in $U S D / h, n_{r}$ the number of resources included in the superstructure, $\mathbf{f}_{\mathbf{r}}$ the utilization factor of the resource $r, C_{O_{w}}$ the operating cost of the technology $w$ in $U S D / h, n_{w}$ the number of technologies included in the superstructure, $\mathbf{f}_{\mathrm{w}}$ the utilization factor of the technology $w, c_{e}^{+}$the cost of electricity buying from the grid, in $U S D / k W h, \dot{\mathbf{E}}_{\text {grid }}^{+}$is the electrical power imported by the system, in $k W_{e}, c_{e}^{-}$the cost of electricity selling to the grid, in $U S D / k W h, \dot{\mathbf{E}}_{\text {grid }}^{-}$the electrical power exported by the system, in $k W_{e}$. This is subject to the constraints of the heat cascade, given by Equation 2 and 3 for each temperature interval $k$ and to the constraints for electricity consumption and exportation, given by Equations 4 to 6 :

$$
\begin{gathered}
\sum_{u=1}^{n_{u}} \mathbf{f}_{\mathbf{u}} \cdot\left(\sum_{h_{k}=1}^{n_{u_{h, k}}} \dot{Q}_{u_{h, k}}-\sum_{c_{k}=1}^{n_{u_{c, k}}} \dot{Q}_{u_{c, k}}\right)+\dot{\mathbf{R}}_{\mathbf{k}+\mathbf{1}}-\dot{\mathbf{R}}_{\mathbf{k}}=0 \quad \forall k=1 \ldots, n_{k} \\
\dot{\mathbf{R}}_{\mathbf{1}}=0 \quad \dot{\mathbf{R}}_{\mathbf{n k + 1}}=0 \quad \dot{\mathbf{R}}_{\mathbf{k}} \geq 0 \quad \forall k=2 \ldots, n_{k} \\
\sum_{u=1}^{n_{u}} \mathbf{f}_{\mathbf{u}} \dot{E}_{\text {grid,u}}^{+}+\dot{\mathbf{E}}_{\text {grid }}^{+}-\sum_{u=1}^{n_{u}} \mathbf{f}_{\mathbf{u}} \dot{E}_{\text {grid }, u}^{-} \geq 0 \\
\sum_{u=1}^{n_{u}} \mathbf{f}_{\mathbf{u}} \dot{E}_{\text {grid,u}}^{+}+\dot{\mathbf{E}}_{\text {grid }}^{+}-\dot{\mathbf{E}}_{\text {grid }}^{-}-\sum_{u=1}^{n_{u}} \mathbf{f}_{\mathbf{u}} \dot{E}_{\text {grid }, u}^{-}=0 \\
\dot{\mathbf{E}}_{\text {grid }}^{+} \geq 0 \quad \dot{\mathbf{E}}_{\text {grid }}^{-} \geq 0
\end{gathered}
$$


where $\mathbf{f}_{\mathbf{u}}$ is the utilization factor of unit $u$ (i.e. resource or technology), $\dot{Q}_{u_{h / c, k}}$ is the thermal heat load of the hot stream $h$ or the cold stream $c$ in the unit $u$ in the temperature interval $k$, in $k W_{t h}$. The hot and cold streams are calculated for the nominal size of each resource, technology or district heating demand added to the problem. An inlet and outlet temperature and a thermal load are associated to each stream. The temperatures of all streams define $n_{k}$ intervals. $\dot{\mathbf{R}}_{\mathbf{k}}$ is then the cascaded heat from the temperature interval $k$ to the lower ones, in $k W_{t h}$, by starting with the higher interval. $\dot{E}_{g r i d, u}^{+}$and $\dot{E}_{g r i d, u}^{-}$are the consumed and exported electricity in $k W_{e}$ by unit $u$, respectively. The constraints on $\dot{\mathbf{E}}_{\text {grid }}^{+}, \dot{\mathbf{E}}_{\text {grid }}^{-}$and $\dot{\mathbf{R}}_{\mathbf{k}}$ guarantee the thermodynamic feasibility.

The utilization factors $\mathbf{f}_{\mathbf{u}}$ are limited by a minimum and a maximum value. The associated integer variables $\mathbf{y}_{\mathbf{u}}$ define if the resource $r$ or the technology $w$ are added to the system $\left(\mathbf{y}_{\mathbf{u}}=1\right)$ or $\operatorname{not}\left(\mathbf{y}_{\mathbf{u}}=0\right)$ :

$$
\mathbf{y}_{\mathbf{u}} \cdot f_{u}^{\min } \leq \mathbf{f}_{\mathbf{u}} \leq \mathbf{y}_{\mathbf{u}} \cdot f_{u}^{\max }
$$

These utilization factors define then the optimal size of each resource and technology. District heating demand temperature-enthalpy profiles have a fixed utilization rate $\left(\mathbf{f}_{\mathbf{u}}=1\right)$. The resolution of this MILP problem (Equations 1 to 7 ) extracts the configuration of the geothermal system from the superstructure and defines the level of usage of the selected technologies and resources. The state variables of this final configuration define then the size of the equipments. $x_{d}$ represents the decision variables of the non-linear master problem, and $\mathbf{f}_{\mathbf{u}}, \dot{\mathbf{R}}_{\mathbf{k}}, \dot{\mathbf{E}}_{\text {grid }}^{-}, \dot{\mathbf{E}}_{\text {grid }}^{+}$, $\mathbf{y}_{\mathbf{u}}$ (in bold) the ones of the MILP slave subproblem.

\subsection{Performance calculation}

Based on the results of the process integration step, indicators of thermo-economic performance are calculated for each period and then combined to obtain the yearly overall performance of the system at the end of the computation sequence. Major ones are presented below.

\subsubsection{Economic performance}

Indicators of economic performance are the investment and operating costs, the levelized cost of district heating (LCDH) and of electricity (LCEL), if the system is used for CHP, the net annual profit and the payback time.

The investment costs, in $U S D$, include the total drilling costs of the geothermal wells, the equipment of the conversion technologies to be used and the district heating network if it has to be built:

$$
C_{i n v}=\sum_{i=1}^{n_{r}} C_{d r i l l, r}\left(x_{d}, \mathbf{f}_{\mathbf{r}}\right)+\sum_{i=1}^{n_{e}} \max \left(C_{i n v, e}\left(x_{d}, \mathbf{f}_{\mathbf{w}}\right)\right)_{n_{p}}+C_{i n v, D H}
$$

where $n_{r}$ is the number of geothermal resources exploited by the system, $C_{d r i l l, r}$ the investment costs of the geothermal wells to exploit resource $r, n_{e}$ the number of equipments of the conversion technologies and the geothermal pumps, $n_{p}$ the number of periods, and $C_{i n v, D H}$ the investment cost of the district heating network. Drilling costs are assessed with the data and formulas provided in (37) for EGS and in (35) for aquifers. Detailed calculations are in Appendix A. The investment costs of the different equipments (i.e. pumps, turbines, flash drums, compressors, boilers and heat exchangers) are calculated using correlations from (43) and (44) for each period $p$. Finally the maximal value over all the periods determines the investment of equipment $e$. An interest rate ir of $6 \%$ and a project lifetime ny of 40 years are assumed to annualize the investment costs:

$$
C_{i n v, a n}=C_{i n v} \cdot \frac{i r \cdot(i r+1)^{n y}}{(i r+1)^{n y}-1}
$$

The system total operating costs, in $U S D / y$ are the sum of the operating costs associated with the different resources and conversion technologies, and the electricity consumed or exported 
by the system, for all periods:

$$
\begin{aligned}
& C_{o p}=\sum_{p=1}^{n_{p}} t_{p} \cdot\left(\sum_{r=1}^{n_{r}} C_{O_{r, p}}\left(x_{d}, \mathbf{f}_{\mathbf{r}}\right)+\sum_{w=1}^{n_{w}} C_{O_{w, p}}\left(x_{d}, \mathbf{f}_{\mathbf{w}}\right)\right. \\
& \left.+c_{e}^{+} \dot{\mathbf{E}}_{\text {grid }, \mathbf{p}}^{+}\left(x_{d}\right)-c_{e}^{-} \dot{\mathbf{E}}_{\text {grid }, \mathbf{p}}^{-}\left(x_{d}\right)-c_{q}^{-} \dot{Q}_{h, p}^{-}\right)
\end{aligned}
$$

where $C_{O_{r, p}}$ is the operating cost of resource $r$, in $U S D / h, C_{O_{w, p}}$ the operating cost of technology $w$, in $U S D / h, t_{p}$ the duration of period $p$, in $h, c_{e}^{+}$the cost of electricity buying, in $U S D / k W h$, $\dot{\mathbf{E}}_{\text {grid,p }}^{+}$the electrical power imported by the system during period $p$, in $k W_{e}, c_{e}^{-}$the cost of electricity selling, in $U S D / k W h, \dot{\mathbf{E}}_{\text {grid,p }}^{-}$the electrical power exported by the system during period $p$, in $k W_{e}, c_{q}^{-}$the cost of district heating selling, in $U S D / k W h$ and $\dot{Q}_{h, p}^{-}$the thermal power required by district heating during period $p$, in $k W_{t h}$.

The levelized cost of district heating is calculated by:

$$
\begin{aligned}
& L C D H=\frac{C_{i n v, a n}\left(i r, n y, x_{d}, \mathbf{f}_{\mathbf{f}}, \mathbf{f}_{\mathbf{W}}\right)}{\sum_{p=1}^{n_{p}} t_{p} \cdot \dot{Q}_{h, p}^{-}} \\
& +\frac{\sum_{p=1}^{n_{p}} t_{p} \cdot\left(\sum_{r=1}^{n_{r}} C_{O_{r, p}}\left(x_{d}, \mathbf{f}_{\mathbf{r}}\right)+\sum_{w=1}^{n_{w}} C_{O_{w, p}}\left(x_{d}, \mathbf{f}_{\mathbf{W}}\right)+c_{e}^{+}\right.}{\left.\dot{\mathbf{E}}_{\text {grid }, \mathbf{p}}^{+}\left(x_{d}\right)+c_{e}^{-} \dot{\mathbf{E}}_{\mathbf{g r i d}, \mathbf{p}}^{-}\left(x_{d}\right)\right)} \\
& \sum_{p=1}^{n_{p}} t_{p} \cdot \dot{Q}_{h, p}^{-}
\end{aligned}
$$

By analogy, the levelized cost of electricity for a CHP system is:

$$
\begin{aligned}
& L C E L=\frac{C_{i n v, a n}\left(i r, n y, x_{d}, \mathbf{f}_{\mathbf{r}}, \mathbf{f}_{\mathbf{w}}\right)}{\sum_{p=1}^{n} t_{p} \cdot \dot{\mathbf{E}}_{\mathbf{g r i d}, \mathbf{p}}^{-}\left(\mathbf{x}_{\mathbf{d}}\right)} \\
& +\frac{\sum_{p=1}^{n_{p}} t_{p} \cdot\left(\sum_{r=1}^{n_{r}} C_{O_{r, p}}\left(x_{d}, \mathbf{f}_{\mathbf{r}}\right)+\sum_{w=1}^{n_{w}} C_{O_{w, p}}\left(x_{d}, \mathbf{f}_{\mathbf{w}}\right)+c_{q}^{-} \dot{Q}_{h, p}^{-}\right)}{\sum_{p=1}^{n_{p}} t_{p} \cdot \dot{\mathbf{E}}_{\mathbf{g r i d}, \mathbf{p}}^{-}\left(\mathbf{x}_{\mathbf{d}}\right)}
\end{aligned}
$$

For the calculation of LCDH, a common selling and buying price of electricity of $0.15 \mathrm{USD} / \mathrm{kWh}$ is assumed. For LCEL, a selling price of heat of $0.10 \mathrm{USD} / \mathrm{kWh}$ is assumed. These values represent an averaging of the Swiss market prices (45).

With the selling prices for both electricity and district heating, the net annual profit generated by the overall geothermal system is then calculated, in $U S D / y$ :

$$
P_{a n}=-\left(C_{i n v, a n}\left(i r, n y, x_{d}, \mathbf{f}_{\mathbf{r}}, \mathbf{f}_{\mathbf{w}}\right)+C_{o p}\left(x_{d}, \mathbf{f}_{\mathbf{r}}, \mathbf{f}_{\mathbf{w}}, c_{e}^{-}, c_{q}^{-}\right)\right)
$$

Finally, the payback time of the installation in years is calculated by:

$$
t_{p b}=\frac{C_{i n v, a n}\left(i r, n y, x_{d}, \mathbf{f}_{\mathbf{r}}, \mathbf{f}_{\mathbf{w}}\right) \cdot n y}{-C_{o p}\left(x_{d}, \mathbf{f}_{\mathbf{r}}, \mathbf{f}_{\mathbf{w}}, c_{e}^{-}, c_{q}^{-}\right)}
$$

\subsubsection{Thermodynamic performance}

Both the energy $\epsilon$ and exergy $\eta$ efficiencies of the conversion system are defined as the ratio between the energy or exergy services produced and the energy or exergy resources entering the conversion system.

If the system is a net importer of electrical power, $\dot{\mathbf{E}}_{\text {grid,p }}^{+}$is used and is accounted in the denominator of Equations 15, 16 and 18. If it is a net exporter, $\dot{\mathbf{E}}_{\text {grid,p }}^{-}$is used and is accounted in the numerator of Equations 15, 16 and 18.

The energy efficiency of the conversion system is then calculated by:

$$
\epsilon=\frac{\sum_{p=1}^{n_{p}} t_{p} \cdot\left(\dot{\mathbf{E}}_{\text {grid }, \mathbf{p}}^{-}\left(x_{d}\right)+\sum_{p=1}^{n_{p}} \dot{Q}_{h, p}^{-}\right)}{\sum_{p=1}^{n_{p}} t_{p} \cdot\left(\dot{\mathbf{E}}_{\text {grid }, \mathbf{p}}^{+}\left(x_{d}\right)+\sum_{r=1}^{n_{r}} \dot{Q}_{r, p}^{+}\left(x_{d}\right)\right)}
$$

The conversion system represents the action system for engineering and is taken as the boundary to calculate exergy efficiency. Thus, reinjection temperature of the resource is used to calculate 
the potential in geothermal exergy available, and the hypothetic cooling down to the ambient temperature is not considered, since it represents a potential anyway not available for the conversion system. The exergy efficiency of the conversion system is calculated by:

$$
\eta=\frac{\sum_{p=1}^{n_{p}} t_{p} \cdot\left(\dot{\mathbf{E}}_{\text {grid }, \mathbf{p}}^{-}\left(x_{d}\right)+\dot{Q}_{h, p}^{-}\left(1-\frac{T_{a}}{T_{h, l m}}\right)\right)}{\sum_{p=1}^{n_{p}} t_{p} \cdot\left(\dot{\mathbf{E}}_{\text {grid }, \mathbf{p}}^{+}\left(x_{d}\right)+\sum_{r=1}^{n_{r}} \dot{Q}_{r, p}^{+}\left(x_{d}\right)\left(1-\frac{T_{a}}{T_{r, l m}}\right)\right)}
$$

where $T_{a}$ is the ambient temperature, assumed to be the cold source, and $T_{l m}$ the log-mean temperature of the hot source, calculated by:

$$
T_{l m}=\frac{T_{\text {in }}-T_{\text {out }}}{\ln \left(\frac{T_{\text {in }}}{T_{\text {out }}}\right)}
$$

where $T_{i n}$ is the inlet temperature of the hot source, either the temperature of the geothermal fluid at well or the district heating return temperature, and $T_{\text {out }}$ the outlet temperature of the hot source, either the reinjection temperature of the fluid or the district heating supply temperature. $T_{r, l m}$ stands for the geothermal resources, and $T_{h, l m}$ for the district heating.

If the system is used for CHP, electrical efficiency is as well calculated:

$$
\epsilon_{e l}=\frac{\sum_{p=1}^{n_{p}} t_{p} \cdot\left(\dot{\mathbf{E}}_{\text {grid, }}^{-}\left(x_{d}\right)\right.}{\sum_{p=1}^{n_{p}} t_{p} \cdot\left(\dot{\mathbf{E}}_{\text {grid }, \mathbf{p}}^{+}\left(x_{d}\right)+\sum_{r=1}^{n_{r}} \dot{Q}_{r, p}^{+}\left(x_{d}\right)\right)}
$$

\subsection{Multi-objective optimization strategy}

The performance indicators selected as objective functions in the non-linear master MOO problem solved by the evolutionary algorithm (34) are the investment costs (Equation 8), to be minimized, and the exergy efficiency of the conversion system (Equation 16), to be maximized. Decision variables of this problem concern the resources and the conversion technologies and are displayed in Table 3. Their values are generated using the multi-period strategy: each decision variable takes a different value for each period, except for the depth of the geothermal resources, which receives a fixed value for all the periods. The range for resources with variable depth is taken from the data of the geological profile (Table 1). The mass flow rate of reinjected geofluid is given as a decision variable only for flash systems ( $1 \mathrm{~F}$ or $2 \mathrm{~F}$ combined with EGS), since there is a material connection between the resource and the technology, the geofluid being directly used. Other technologies have only a heat exchange between the geofluid and the technology, and the optimal size of the resource is then calculated at the process integration step (Equations 1 to 7). The superstructure includes two heat pumps with different operating conditions, in order to decrease the exergy losses due to the heat transfer between the geofluid and the evaporating fluid, and between the heat demand and the condensing fluid. In terms of operating cost, the competition between boiler, heat pump and cogeneration unit depends mainly on the ratio between the fuel and the electricity price. As this is the objective function of the slave optimization, it is needed to use this ratio as a decision variable of the master problem to explore the whole space of the related investment for equipment linked with its different potential sizes.

All the clusters corresponding to the potential combinations of resources and technologies are evaluated. A Pareto curve is calculated for each one of them.

\section{Results}

\subsection{Comparison of all resources and technologies}

The results of the MOO are displayed in Figure 3. The clusters with EGS include as well the potential combinations of flash and ORC systems. All the combinations of resources and 


\begin{tabular}{|c|c|c|c|c|}
\hline Name & $\begin{array}{l}\text { Resource/ } \\
\text { Technology }\end{array}$ & $\mathbf{M P}^{\mathrm{a}}$ & Range & Unit \\
\hline Depth of resource & $\begin{array}{l}\text { EGS } \\
\text { DA-1300 } \\
\text { SA-600 }\end{array}$ & no & $\begin{array}{l}{[3000 ; 10000]} \\
{[1130 ; 1300]} \\
{[300 ; 600]}\end{array}$ & $m$ \\
\hline $\begin{array}{l}\text { Reinjection temperature } \\
\text { of geofluid }\end{array}$ & $\begin{array}{l}\text { EGS } \\
\text { DA, SA }\end{array}$ & yes & $\begin{array}{l}{[70 ; 130]} \\
{[8 ; 30]}\end{array}$ & ${ }^{\circ} \mathrm{C}$ \\
\hline $\begin{array}{l}\text { Mass flow rate of reinjected ge- } \\
\text { ofluid }\end{array}$ & $1 \mathrm{~F}, 2 \mathrm{~F}$ & yes & {$[10 ; 50]$} & $\mathrm{kg} / \mathrm{s}$ \\
\hline $\begin{array}{l}\text { Flashing pressure of } 1 \text { st flash } \\
\text { drum }\end{array}$ & $1 \mathrm{~F}, 2 \mathrm{~F}$ & yes & {$[2 ; 12]$} & bar \\
\hline $\begin{array}{l}\text { Flashing pressure of } 2 \text { nd flash } \\
\text { drum }\end{array}$ & $2 \mathrm{~F}$ & yes & {$[2 ; 12]$} & bar \\
\hline ORC evaporation temperature & $\begin{array}{l}\text { ORC-s, ORC- } \\
\text { d }\end{array}$ & yes & {$[90 ; 135]$} & ${ }^{\circ} \mathrm{C}$ \\
\hline $\begin{array}{l}\text { Temperature difference between } \\
\text { ORC superheating and geofluid }\end{array}$ & $\begin{array}{l}\text { ORC-s, ORC- } \\
\text { d }\end{array}$ & yes & {$[5 ; 20]$} & ${ }^{\circ} \mathrm{C}$ \\
\hline $\begin{array}{l}\text { ORC intermediate draw-off } \\
\text { temperature }\end{array}$ & ORC-d & yes & {$[20 ; 65]$} & ${ }^{\circ} \mathrm{C}$ \\
\hline $\begin{array}{l}\text { Fraction of intermediate draw- } \\
\text { off going for district heating }\end{array}$ & ORC-d & yes & {$[0.05 ; 0.95]$} & - \\
\hline HP1 evaporation temperature & HP & yes & {$[2 ; 55]$} & ${ }^{\circ} \mathrm{C}$ \\
\hline HP2 evaporation temperature & $\mathrm{HP}$ & yes & {$[2 ; 55]$} & ${ }^{\circ} \mathrm{C}$ \\
\hline HP1 condensation temperature & HP & yes & {$[20 ; 70]$} & ${ }^{\circ} \mathrm{C}$ \\
\hline HP2 condensation temperature & $\mathrm{HP}$ & yes & {$[20 ; 70]$} & ${ }^{\circ} \mathrm{C}$ \\
\hline $\begin{array}{l}\text { Temperature difference between } \\
\text { HP1 condensation and subcool- } \\
\text { ing }\end{array}$ & HP & yes & {$[0 ; 20]$} & ${ }^{\circ} \mathrm{C}$ \\
\hline $\begin{array}{l}\text { Temperature difference between } \\
\text { HP2 condensation and subcool- } \\
\text { ing }\end{array}$ & HP & yes & {$[0 ; 20]$} & ${ }^{\circ} \mathrm{C}$ \\
\hline Electricity price ${ }^{\mathrm{b}}$ & $\mathrm{HP}$ & no & {$[0.05 ; 0.30]$} & $U S D / k W h$ \\
\hline Natural gas price ${ }^{\mathrm{b}}$ & HP & no & {$[0.05 ; 0.30]$} & $U S D / k W h$ \\
\hline
\end{tabular}

${ }^{\mathrm{a}} \mathrm{MP}$ is yes if the variable is considered for each period.

b These two parameters vary in order to explore the whole space of the potential investment costs related with the equipment which operating costs are optimized in the slave sub-problem.

Table 3: Decision variables used for the different multi-objective optimization scenarios 
technologies present a trade-off between the investment costs and the exergy efficiency, except for the deep aquifer at $2500 \mathrm{~m}$, for which a unique solution is obtained, the temperature of the resource being sufficient to directly supply the district heating. The other aquifers all require a combination of heat pumps and a boiler to produce the high temperature heat for domestic hot water or for winter conditions. The colored arrows point at the typical configurations that are discussed in details in subsection 3.2. For both investment costs and exergy efficiency, the best

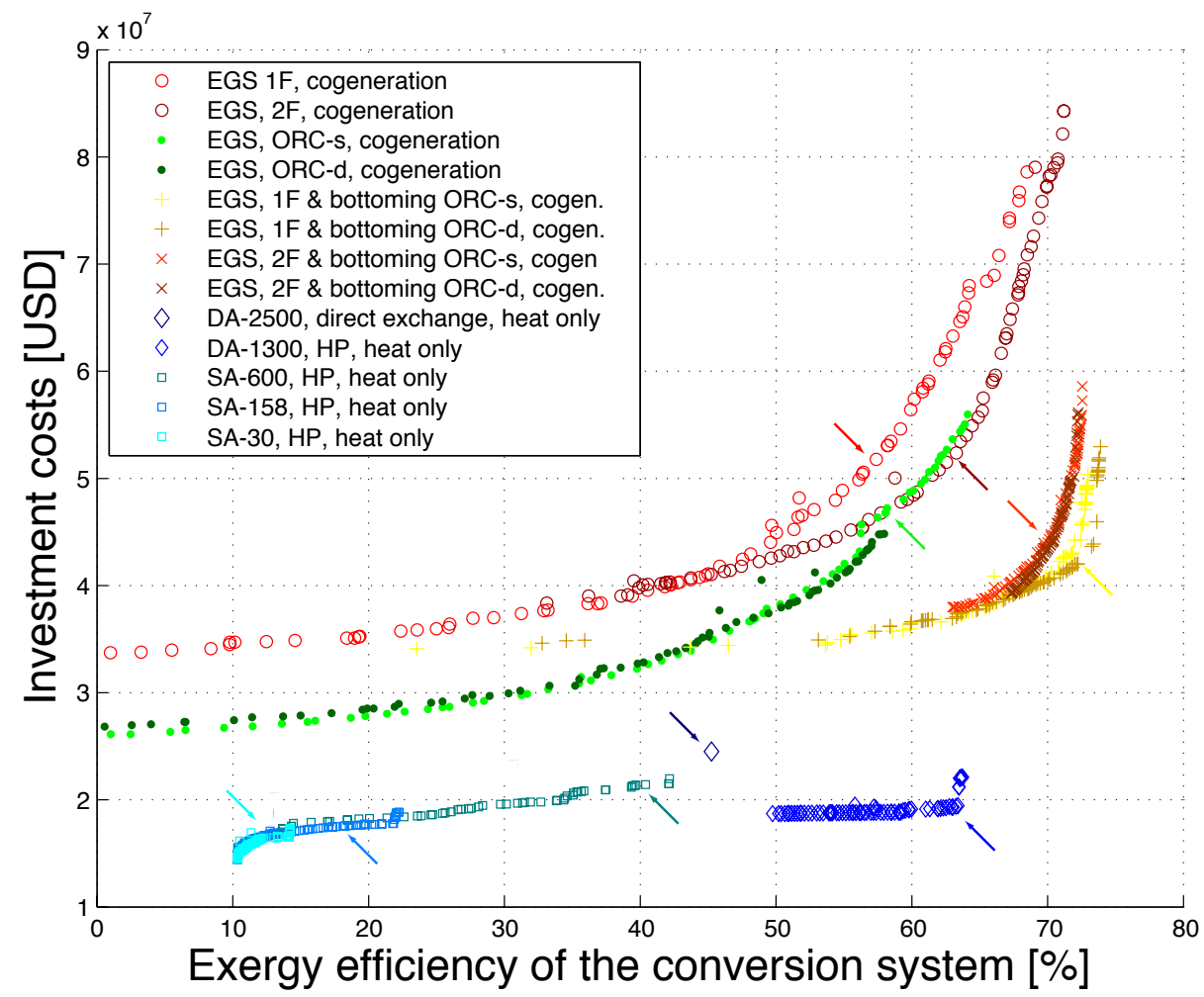

Figure 3: Pareto curves of the clusters of resources and technologies for the case study

configurations are either the deep aquifers between 1300 and $1130 \mathrm{~m}$ with a heat pump having a good coefficient of performance, or an EGS with a single flash and a bottoming ORC for CHP, with higher exergy efficiency but higher investment costs. EGS used for CHP can reach exergy efficiencies of the conversion system of around $60 \%$ for all technologies. This performance goes higher than $70 \%$ for flash systems with bottoming ORCs. The exergy efficiency, the investment costs, and the best CHP technology are however strongly dependent on the depth of the EGS. This particular aspect is discussed more in details in subsection 3.3.

For the configurations using heat pumps, the lower are the exergy efficiency and the investment costs, the more the boiler is used. For some of the configurations with shallow aquifers, the use of a two heat pump system allows to increase the exergy efficiency. Typical configurations representative of the different Pareto curves of Figure 3 are analyzed and compared at subsection 3.2 .

\subsection{Analysis of typical configurations}

For each configuration, the repartition on the levelized cost of district heating (LCDH) of the annualized investment, operating costs and electricity sellings for CHP systems is displayed in Figure 4. The configurations selected for EGS have a depth of $6000 \mathrm{~m}\left(220^{\circ} \mathrm{C}\right.$ at well). The payback time (Equation 14) of the configuration, when lower than the project lifetime of 40 years, is as well indicated on the figure. For deep aquifers and CHP systems, the operating costs excluding the electricity sellings have a much lower contribution to the LCDH than the 

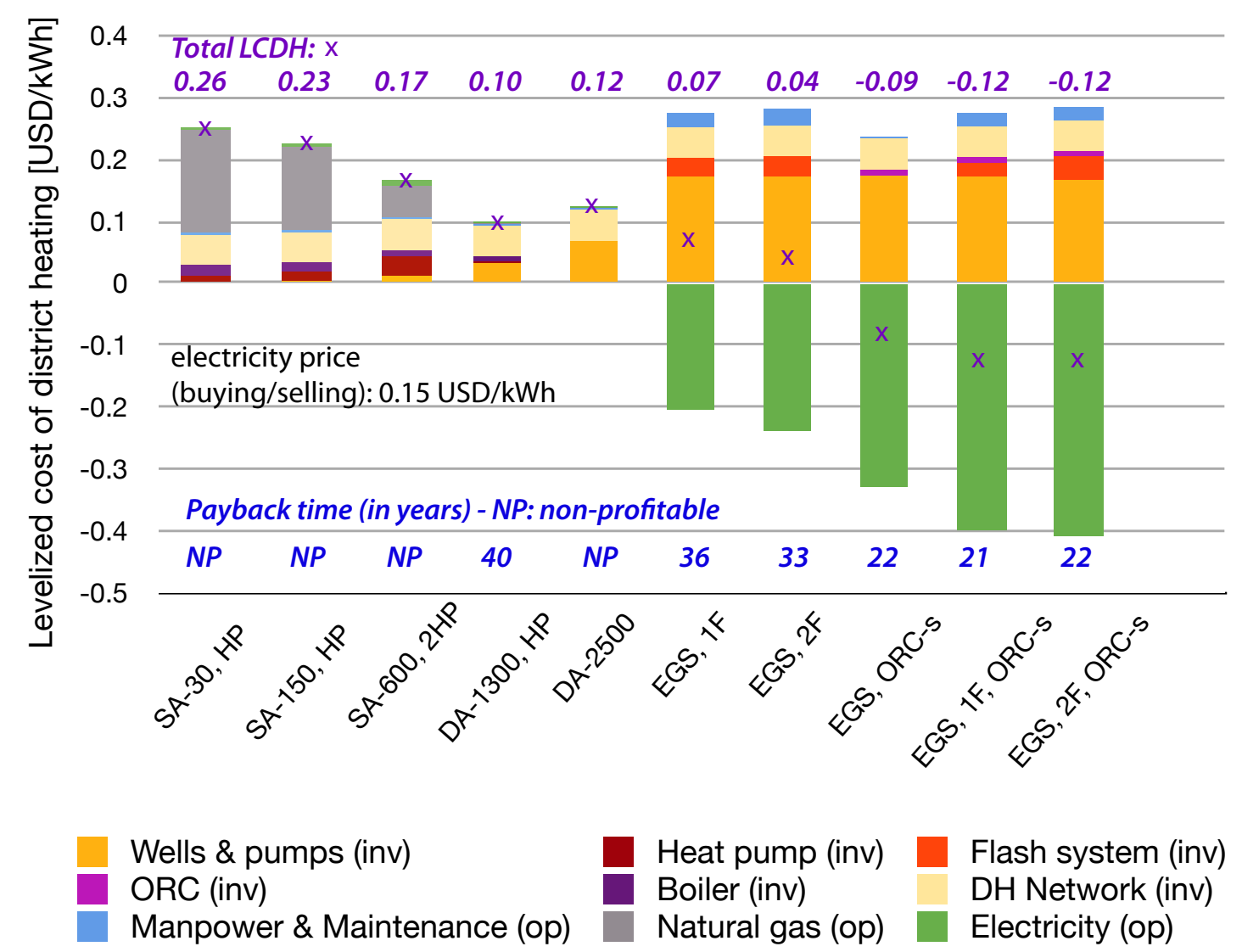

Flash system (inv) DH Network (inv) Electricity (op)

Figure 4: Analysis of representative typical configurations from Pareto curves of Figure 3

investment costs. For shallow aquifers, they have a more important share, due to the use of the gas boiler, the thermal power available in the geothermal resource being limited when compared with the demand. The available thermal power is increasing with depth, due to the increasing temperature and to the assumed constant mass flow rate. The three configurations of shallow aquifers are not competitive, because of the investment linked with the wells for a low thermal power. For the two configurations with deep aquifers, the investment costs linked with the drilling of the wells become increase, while all the costs linked with the conversion system decrease. For the aquifer at $1300 \mathrm{~m}$, a small heat pump and a boiler are necessary, but this configuration performs better than the deeper one at $2500 \mathrm{~m}$ with a direct exchange and no boiler. Among configurations without CHP, this one is the only profitable regarding payback time and its LCDH (0.10 USD/kWh), comparable to the cost of house-heating with an individual gas boiler.

All CHP systems have a lower LCDH than the configurations supplying only district heating. Though the investment costs, dominated by the drilling of wells, are much higher, they are compensated by the electricity sellings. The conversion cycle has a low share, especially for ORCs. At a $6000 \mathrm{~m}$ depth, flash systems alone have a lower performance than ORCs and than flash systems with bottoming ORCs, which all have a negative LCDH and are thus profitable for single electricity production. The influence of depth on EGS configurations is discussed more in details in subsection 3.3.

A deeper analysis of the typical configurations highlights the strength of the multi-period approach used for system design. For each period, the system design can be represented and analyzed by considering the seasonal composite curves and its associated performances. Figure 5 shows the integration of the ORC within the overall system for each period, for the configuration of the EGS combined with single-flash system and bottoming ORC. The integrated composite curve (46) of the ORC is presented in red, while the Grand composite curve of the other units (liquid part of flashed geothermal water, cold source and heating demand) are in blue. The area 


\begin{tabular}{|l|c|c|c|c|}
\hline & Interseason & Winter & Summer & Extreme \\
\hline Thermal power EGS $\left[k W_{t h}\right]$ & 13838 & 22313 & 6721 & 19090 \\
Exergy EGS $[k W]$ & 4534 & 7291 & 2206 & 6287 \\
Injection temperature $\left[{ }^{\circ} \mathrm{C}\right]$ & 76 & 75 & 76 & 78 \\
ORC evap. temperature $\left[{ }^{\circ} \mathrm{C}\right]$ & 116 & 128 & 102 & 104 \\
ORC supheat. temperature $\left[{ }^{\circ} \mathrm{C}\right]$ & 168 & 173 & 163 & 177 \\
Flashing pressure $[\mathrm{bar}]$ & 10 & 11 & 8 & 11 \\
\hline Electrical power $1 \mathrm{~F}\left[k W_{e}\right]$ & 1571 & 2487 & 921 & 2170 \\
Electrical power $\mathrm{ORC}\left[k W_{e}\right]$ & 1975 & 3200 & 741 & 2294 \\
Parasitic losses $\left[k W_{e}\right]$ & 280 & 449 & 137 & 392 \\
Thermal power DH $\left[k W_{t h}\right]$ & 950 & 2200 & 500 & 3100 \\
Exergy DH $[k W]$ & 62 & 206 & 34 & 373 \\
\hline Exergy efficiency $[-]$ & 73.4 & 74.7 & 70.6 & 70.7 \\
Energy efficiency $[-]$ & 30.5 & 33.3 & 30.1 & 37.6 \\
Electrical efficiency $[-]$ & 23.6 & 23.5 & 22.7 & 21.3 \\
\hline
\end{tabular}

Table 4: Multi-period values for decision variables, operating conditions and performances for the example of Figure 5

between the two curves shows the exergy losses due to the heat transfer inside the conversion system. The figure allows to visualize as well the location of the pinch points for the ORC integration. The details of the values for the multi-period decision variables, the resulting operating conditions and the seasonal performance indicators are displayed in Table 4. This highlights the
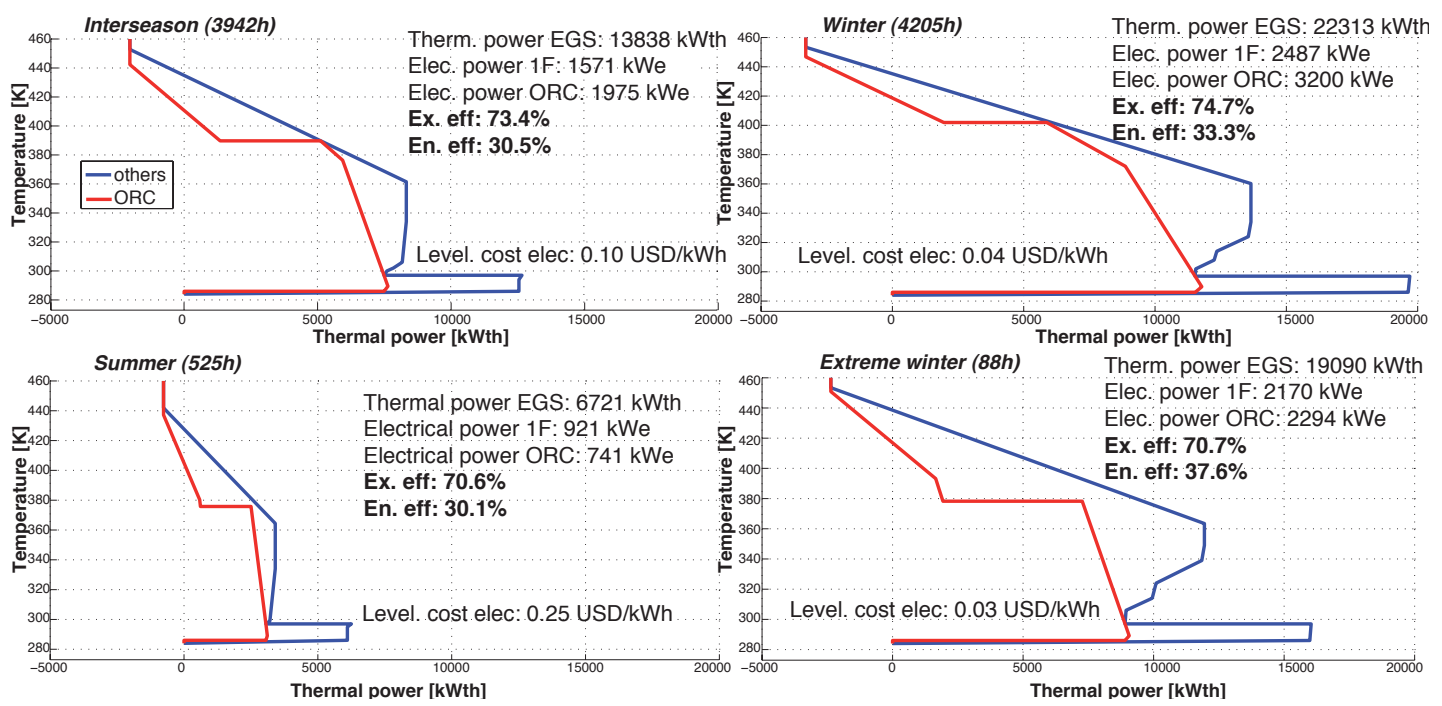

Figure 5: Example of a multi-period integrated composite of an ORC with single-flash system (EGS, 1F, ORC-s of Figure 4) and associated values of operating parameters

seasonal variation of the system optimal operating size, since the utilization rate of the geofluid is a decision variable. Thus, the thermal power used from the EGS varies depending on the season, in order to maximize the seasonal exergy efficiency of the conversion system, which depends on the ratio between the produced electricity and the district heating requirements. Therefore, during winter periods, the used fraction of the available thermal power is much higher than during periods with a lower district heating requirement (i.e. interseason and summer). Hence, the electricity production is as well higher in winter and lower in summer, even if the district heating requirements are higher in winter. This result is significant in the context of the Swiss market electricity, Switzerland being a net importer of electricity in winter, and a net exporter in 
summer (47). Moreover, the calculation of the levelized cost of electricity per period, displayed on Figure 5 indicates as well that electricity production from this system is more attractive in winter.

The operating conditions of the conversion system, such as the evaporation temperature of the working fluid in the ORC, its superheating temperature, and the flashing pressure of the flash drum, are optimized for each period, except for the extreme winter conditions, Figure 5 showing potential for further reduction of exergy losses. The shortness of this period ( $88 \mathrm{~h})$ makes it difficult to optimize it by the multi-period MOO strategy.

In addition, the difference between the energy and the electrical efficiency in Table 4 indicates that CHP increases significantly the energy efficiency of the geothermal resource usage. This benefit goes from 7 to $10 \%$ for significant periods, which is important when relatively compared with the electrical efficiency. The contribution of district heating to the increase of the exergy efficiency is however much less important.

\subsection{Influence of depth on EGS}

For EGS, depth of the resource controls the trade-off between exergy efficiency and investment costs. This is shown in Figure 6, where Pareto curves for the clusters with EGS are plotted with the depth in color gradient. Except for single and double flash systems without a bottoming ORC,

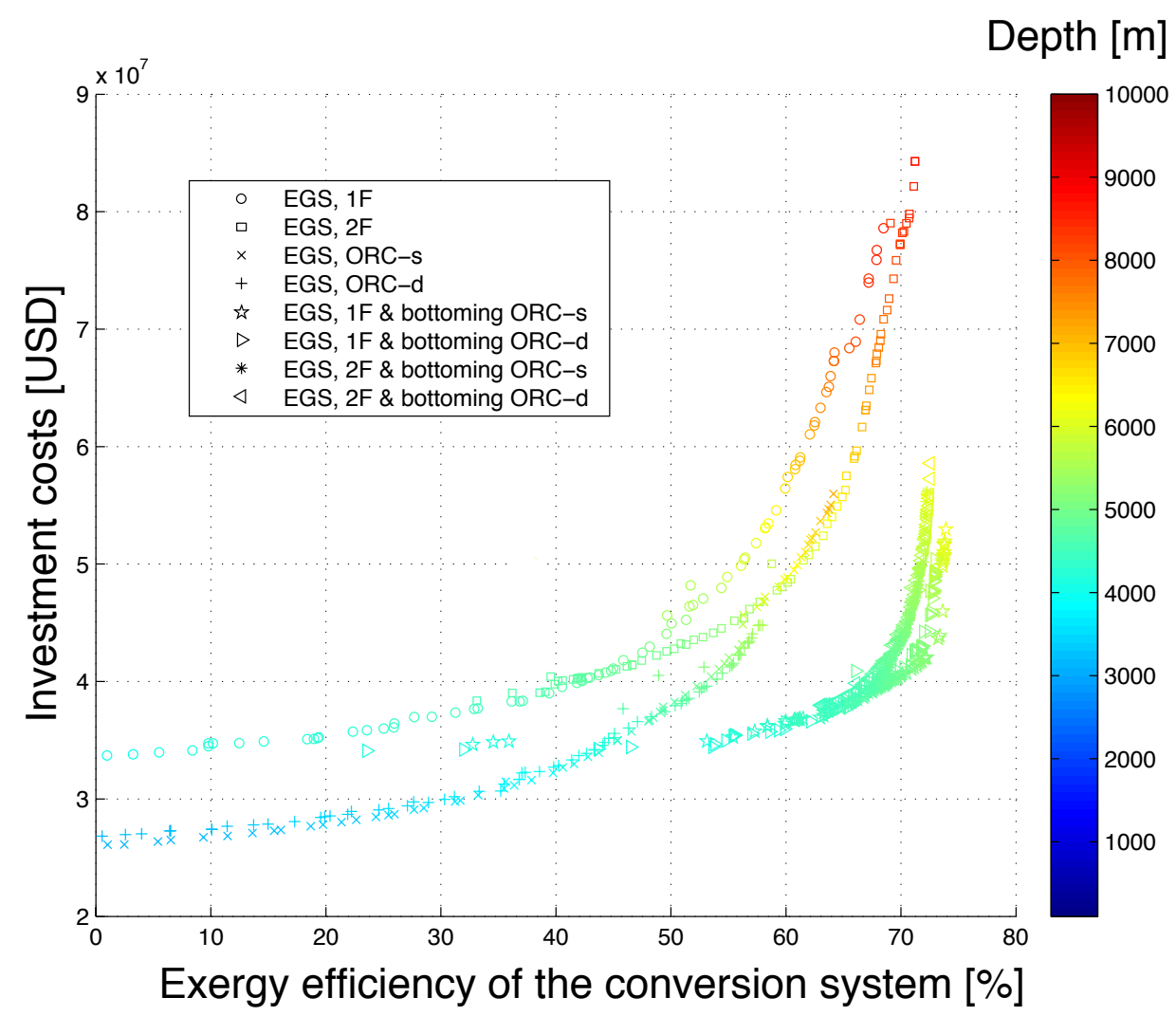

Figure 6: Influence of depth of EGS on the different combinations of technologies

the optimal range of depths for the exploitation of EGS does not go above 6000 to $7000 \mathrm{~m}$. Beyond, the exergy efficiency of the conversion system is not increased anymore by higher investment costs in the drilling of deeper wells. For the same reason, no solution for flash systems alone was retained in the highest range between $8000 \mathrm{~m}$ to $10000 \mathrm{~m}$. All clusters present optimal solutions in the lowest range, around 3000 to $4000 \mathrm{~m}$, but their exergy efficiency is low and can be significantly increased with little additional investment in deeper wells.

These results are further interpreted in terms of levelized cost of district heating (LCDH) 
and of electricity (LCEL), by analyzing a reduced number of representative points. For each cluster of technologies, one point is chosen each $1000 \mathrm{~m}$ when the solution exists, from 4000 to $8000 \mathrm{~m}$. The LCDH and LCEL are displayed in Figures 7 and 8, assuming a selling price of 0.15 $U S D / k W h$ and $0.10 U S D / k W h$ for net produced electricity and district heating, respectively. The LCDH shows a fairly linear trend and keeps decreasing with deeper wells, while the LCEL

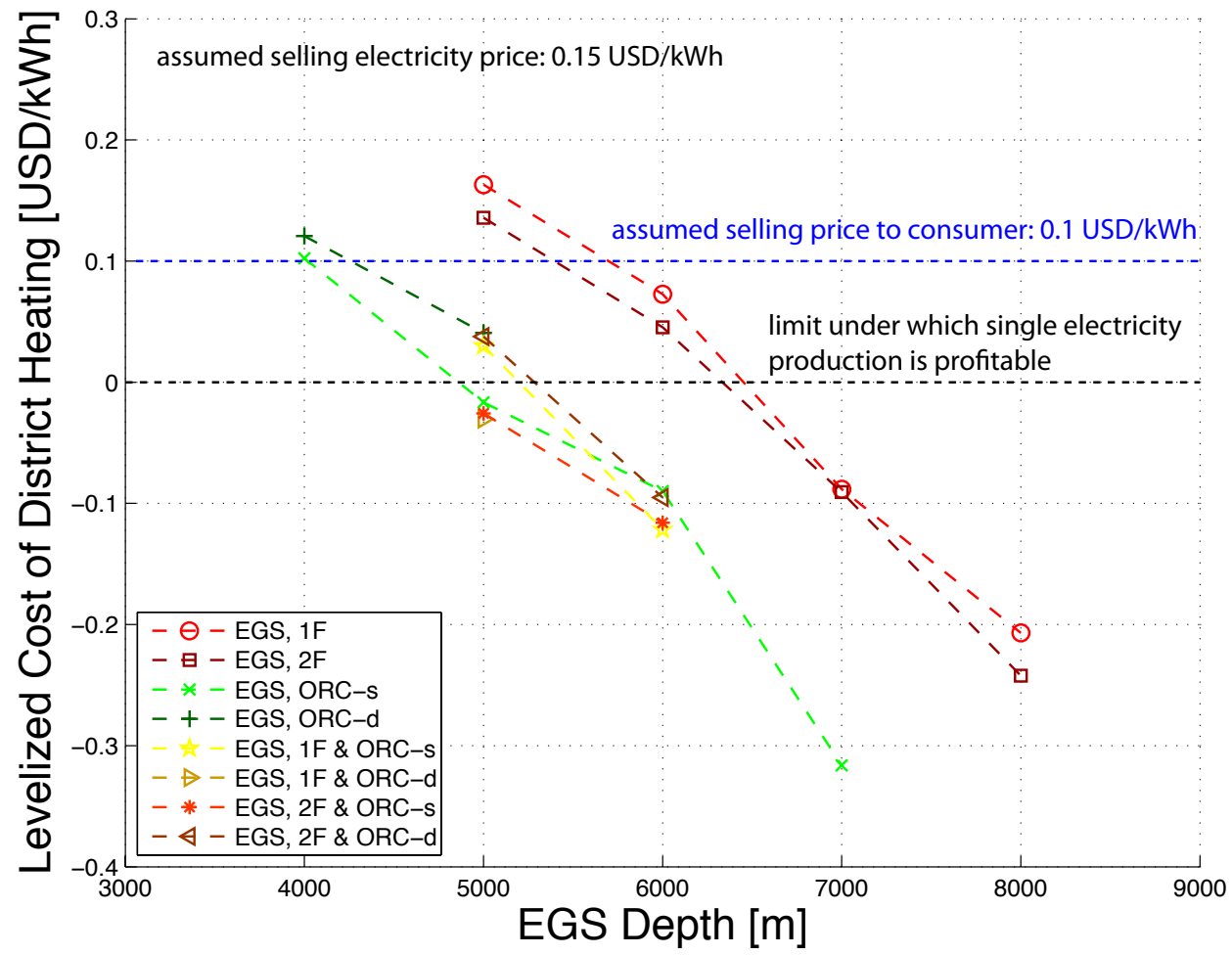

Figure 7: Levelized cost of district heating for EGS, using different technologies and depths

decreases first drastically, and tends then to stabilize.

At $4000 \mathrm{~m}\left(140^{\circ} \mathrm{C}\right.$ at well), only ORCs can be used because of the low temperature. This situation is however not profitable. Between $5000 \mathrm{~m}$ and $6000 \mathrm{~m}\left(220^{\circ} \mathrm{C}\right.$ at well $)$, all technologies can be used, but only ORCs or flash systems with bottoming ORCs are profitable. At $7000 \mathrm{~m}$ $\left(260^{\circ} \mathrm{C}\right.$ at well), the combination of flash systems and bottoming ORCs is not interesting anymore, and the ORC is the best configuration which can be selected for this case study. At $8000 \mathrm{~m}$ $\left(300^{\circ} \mathrm{C}\right.$ at well), only flash systems are remaining, but the levelized costs start increasing again, due to the increased drilling investment and to the change of technology.

The trade-off between these increased drilling costs and the additional electricity produced is sensitive to the market prices for electricity and district heating. This effect is studied by a sensitivity: the net annual profit (Equation 13) is calculated for all the points of Figures 7 and 8 , and for each ratio between electricity and district heating prices, the best configuration is selected. Results are presented in Figure 9. Three domains are drawn. The first one, at 0.05 USD/kWh and below both for electricity and district heating, represents the domain where an EGS is not profitable. In the second domain, with electricity prices from 0.05 to $0.25 \mathrm{USD} / \mathrm{kWh}$, an ORC with an EGS built at a depth of $7000 \mathrm{~m}$ is the most profitable. Though this option is the best technology for a wide domain, for some of the points of Figure 9, it has to be pointed that its performance is very close to the combination of flash systems and bottoming ORCs at $6000 \mathrm{~m}$. In the third domain, if electricity selling prices are higher than $0.25 \mathrm{USD} / \mathrm{kWh}$, it is worth investing in a deeper EGS, at $8000 \mathrm{~m}$, and use a double-flash system.

Finally, it has to be underlined that these results are sensitive to other uncertain economic parameters, the most important of them being the costs of drilling, linked with the oil and gas 


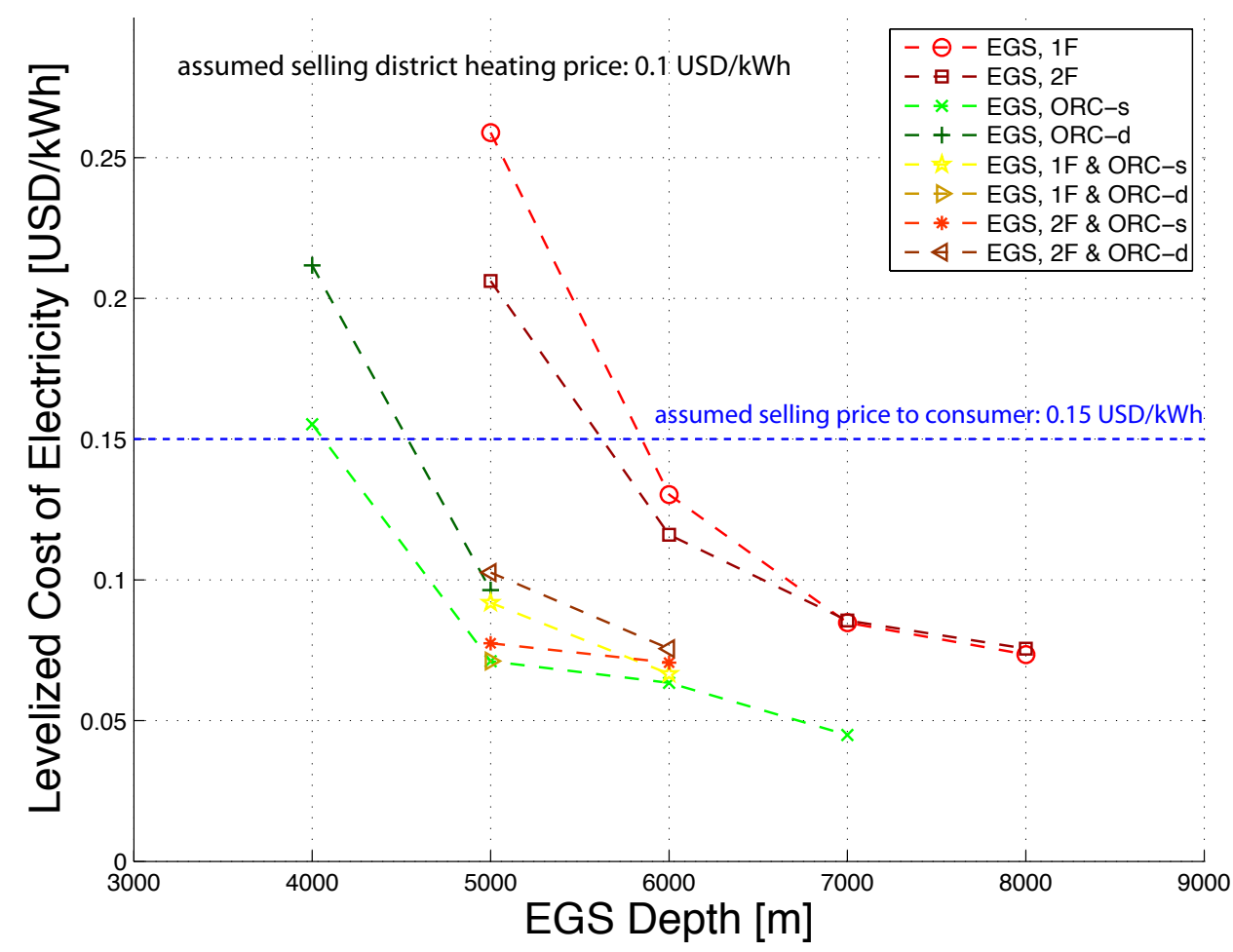

Figure 8: Levelized cost of electricity for EGS, using different technologies and depths

prices on the market. It has also to be reminded that these results are valid only for the geological conditions and the district heating demand of the case study, especially the expected flow rates.

\section{Conclusions}

A systematic methodology for the design of geothermal energy conversion systems in urban areas has been presented, combining geo-localized potential resources, usable conversion technologies and geo-localized seasonal data of the demand in energy services. Process integration, process design and multi-objective optimization techniques are used to calculate the system optimal configurations.

The results of an application case study shows the benefits of the multi-period strategy to adapt the operation of the system to the seasonal conditions. It highlights as well important effects that have to be accounted for in the design of geothermal systems. For the exploitation of deep and shallow aquifers, a trade-off exists between the investment linked with the drilling of the wells, allowing to reach higher temperature resources, and the investment costs linked with the heat pump system, the consumed electricity and the back-up system, increasing when the depth and the temperature decrease. Thus, the optimal exploitation depth depends on the costs of drilling, electricity and natural gas, and on the expected thermal power available from the aquifer.

When compared with aquifers for single district heating supply, the future exploitation of enhanced geothermal systems for combined heat and power production is attractive, the additional investment linked with a deeper resource being compensated by the additional income from electricity. In the geological conditions of the case study, it has been demonstrated that enhanced geothermal systems built at an optimal depth and using the appropriate conversion technology can be profitable even in the case both district heating and electricity selling prices are low. The performance of the system, in terms of levelized cost of energy, is increasing up to a certain optimal depth where it is decreasing again due to the investment costs and to a 


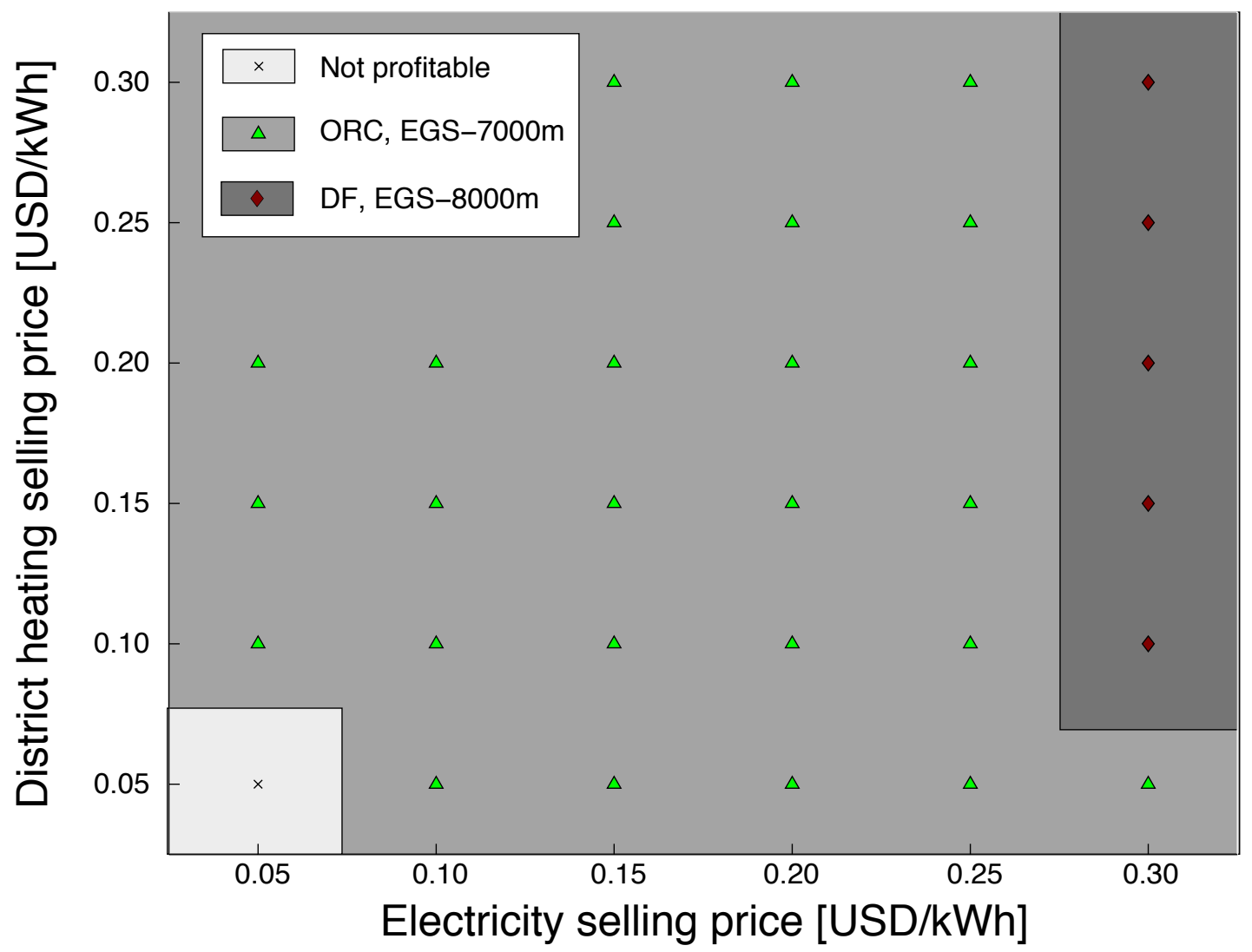

Figure 9: Best technology and resource in function of the electricity and district heating selling price

change in the technology, from ORCs or flash-systems with bottoming ORCs to flash systems alone. Thus, though current projects for enhanced geothermal systems like Soultz-sous-Forêts or the former project of Basel are based on a depth of $5000 \mathrm{~m}$, once enhanced geothermal systems are a mature technology, the exploitation of deeper resources is worth the investment if similar water mass flow rates can be obtained.

The results obtained with the developed methodology demonstrate therefore the potential for the exploitation of deep geothermal resources and their integration in urban energy systems for combined heat and power production.

\section{Acknowledgements}

The present study represents part of the research project Geotherm funded by the Competence Center Environment and Sustainability of the ETH Domain (CCES).

\section{References}

[1] J. Lund and R. Bertani, "Worldwide Geothermal Utilization 2010," in Geothermal Resources Council Transactions, vol. 34, pp. 182-185, 2010.

[2] IEA, "Technology Roadmap - Geothermal Heat and Power," tech. rep., International Energy Agency, Paris, France, 2011.

[3] U. Desideri and G. Bidini, "Study of possible optimisation criteria for geothermal power plants," Energy Conversion and Management, vol. 38, pp. 1681-1691, 1997. 
[4] H. Hettiarachchi, M. Golubovic, W. Worek, and Y. Ikegami, "Optimum design criteria for an Organic Rankine cycle using low-temperature geothermal heat sources," Energy, vol. 32, pp. 1698-1706, 2007.

[5] B. Saleh, G. Koglbauer, M. Wendland, and J. Fischer, "Working fluids for low-temperature organic Rankine cycles," Energy, vol. 32, pp. 1210-1221, 2007.

[6] A. Franco and M. Villani, "Optimum design of binary cycle power plants for waterdominated, medium-temperature geothermal fields," Geothermics, vol. 38, pp. 379-391, 2009 .

[7] J. Sun and W. Li, "Operation optimization of an organic rankine cycle (ORC) heat recovery plant," Applied Thermal Engineering, vol. 31, pp. 2032-2041, 2011.

[8] S. Quoilin, S. Declaye, B. Tchanche, and V. Lemort, "Thermo-economic optimization of waste heat recovery Organic Rankine cycles," Applied Thermal Engineering, vol. 31, pp. 2885-2893, 2011.

[9] Z. Gu and H. Sato, "Performance of supercritical cycles for geothermal binary design," Energy Conversion and Management, vol. 43, pp. 961-971, 2002.

[10] G. Angelino and P. C. DiPaliano, "Multicomponent Working Fluids for Organic Rankine Cycles (ORCs)," Energy, vol. 23, pp. 449-463, 1998.

[11] A. Lazzaretto, A. Toffolo, G. Manente, N. Rossi, and M. Paci, "Cost Evaluation of organic Rankine cycles for Low temperature geothermal sources," in Proceedings of the 24th International Conference on Efficiency, Cost, Optimization, Simulation and Environmental Impact of Energy Systems, pp. 3854-3868, 2011.

[12] M. Kanoglu, Y. Cengel, and R. Turner, "Economic evaluation of geothermal power generation, heating, and cooling," Energy, vol. 24, pp. 501-509, 1999.

[13] F. Heberle and D. Brüggemann, "Exergy based fluid selection for a geothermal Organic Rankine Cycle for combined heat and power generation," Applied Thermal Engineering, vol. 30, pp. 1326-1332, 2010.

[14] T. Guo, H. Wang, and S. Zhang, "Selection of working fluids for a novel low-temperature geothermally-powered ORC based cogeneration system," Energy Conversion and Management, vol. 52, pp. 2384-2391, 2011.

[15] T. Guo, H. Wang, and S. Zhang, "Fluids and parameters optimization for a novel cogeneration system driven by low-temperature geothermal sources," Energy, vol. 36, pp. 2639-2649, 2011.

[16] R. DiPippo, "Second Law assessment of binary plants generating power from lowtemperature geothermal fluids," Geothermics, vol. 33, pp. 565-586, 2004.

[17] C. Coskun, Z. Oktay, and I. Dincer, "Performance evaluations of a geothermal power plant," Applied Thermal Engineering, vol. 31, pp. 4074-4082, 2011.

[18] M. Kanoglu and I. Dincer, "Performance assessment of cogeneration plants," Energy Conversion and Management, vol. 50, pp. 76-81, 2009.

[19] L. Ozgener, A. Hepbasli, I. Dincer, and M. Rosen, "Exergoeconomic analysis of geothermal district heating systems: A case study," Applied Thermal Engineering, vol. 27, pp. 13031310, 2007. 
[20] L. Ozgener, A. Hepbasli, and I. Dincer, "Exergy analysis of two geothermal district heating systems for building applications," Energy Conversion and Management, vol. 48, pp. 1185$1192,2007$.

[21] M. Beck, J. Hecht-Méndez, M. dePaly, P. Bayer, P. Blum, and A. Zell, "Optimization of the Energy Extraction of a Shallow Geothermal System," in IEEE World Congress on Computational Intelligence, WCCI 2010 - 2010 IEEE Congress on Evolutionary Computation, CEC 2010, art. no. 5585921, 2011.

[22] B. Linnhoff, D. Townsend, D. Boland, G. Hewitt, B. Thomas, A. Guy, and R. Marsland, User Guide on Process Integration for the Efficient Use of Energy. Rugby, Warks, England: The Institution of Chemical Engineers, 1982.

[23] C. A. Floudas, A. Ciric, and I. Grossmann, "Automatic Synthesis of Optimum Heat Exchanger Network Configurations," AIChE Journal, vol. 32, pp. 276-290, 1986.

[24] F. Maréchal and B. Kalitventzeff, "Process integration: Selection of the optimal utility system," Computers \& Chemical Engineering, vol. 22, pp. S149-S156, 1998.

[25] F. Maréchal and B. Kalitventzeff, "Targeting the integration of multi-period utility systems for site scale process integration," Applied Thermal Engineering, vol. 23, pp. 1763-1784, 2003.

[26] I. Kemp, Pinch Analysis and Process Integration: A User Guide on Process Integration for the Efficient Use of Energy. Amsterdam, Netherlands: Elsevier Butterworth-Heinemann, 2007.

[27] S. Perry, J. Klemes, and I. Bulatov, "Integrating waste and renewable energy to reduce the carbon footprint of locally integrated energy sectors," Energy, vol. 33, pp. 1489-1497, 2008.

[28] P. Varbanov and J. Klemes, "Integration and management of renewables into Total Sites with variable supply and demand," Computers and Chemical Engineering, vol. 35, pp. 1815$1826,2011$.

[29] M. Gassner, F. Vogel, G. Heyen, and F. Maréchal, "Optimal process design for the polygeneration of SNG, power and heat by hydrothermal gasification of waste biomass: Thermoeconomic process modelling and integration," Energy and Environmental Science, vol. 4, pp. 1726-1741, 2011.

[30] M. Gassner and F. Maréchal, "Methodology for the optimal thermo-economic, multiobjective design of thermochemical fuel production from biomass," Computers $\& 5$ Chemical Engineering, vol. 33, pp. 769-781, 2009.

[31] L. Tock, M. Gassner, and F. Maréchal, "Thermochemical production liquid fuels from biomass: Thermo-economic modeling, process design and process integration analysis," Biomass and Bioenergy, vol. 34, pp. 1838 - 1854, 2010.

[32] M. Hoban, L. Gerber, and F. Maréchal, "Integrated Thermo-economic Modeling of Geothermal Resources for Optimal Exploitation Scheme Identification," in Proceedings of the 23rd International Conference on Efficiency, Cost, Optimization, Simulation and Environmental Impact of Energy Systems, pp. 2239-2246, 2010.

[33] C. Weber, F. Maréchal, and D. Favrat, "Design and optimization of district energy systems," Computer Aided Chemical Engineering, vol. 24, pp. 1127-1132, 2007. 
[34] A. Molyneaux, G. Leyland, and D. Favrat, "Environomic multi-objective optimisation of a district heating network considering centralized and decentralized heat pumps," Energy, vol. 35 , pp. $751-758,2010$.

[35] J. Wilhelm, G. Bianchetti, and F.-D. Vuataz, "Assessment of the geothermal potential of the canton of Vaud," tech. rep., Groupement PGV, Lausanne, Switzerland, 2003.

[36] Working Group PDGN, "Cantonal program for geothermal development in Neuchâtel: Final report," tech. rep., Swiss Laboratory for Geothermics - CREGE, Neuchâtel, Switzerland, 2010.

[37] J. Tester, B. Anderson, A. Batchelor, D. Blackwell, R. DiPippo, E. Drake, J. Garnish, B. Livesay, M. Moore, K. Nichols, S. Petty, M. Toksoz, and R. Veatch, "The Future of Geothermal Energy - Impact of Enhanced Geothermal Systems (EGS) on the United States in the 21st Century," tech. rep., Massachusetts Institute of Technology, Cambridge, Massachusetts, USA, 2006.

[38] J. Sprecher, "Tridimensional modeling of the deep geology of the Molassic Plateau of Western Switzerland." Master thesis effectuated at Ecole Polytechnique Fédérale de Lausanne, Switzerland, 2011.

[39] R. DiPippo, Geothermal Power Plants: Principles, Applications, Case Studies and Environmental Impacts. Oxford, UK: Butterworth-Heinemann c/o Elsevier, 2008.

[40] www.belsim.com, official website of the Belsim company, Awans, Belgium, last date of access: 18.10.2011.

[41] N. Cuenot, J.-P. Faucher, D. Fritsch, A. Genter, and D. Szablinski, "The European EGS project at Soultz-sous-Forêts: from extensive exploration to power production," in IEEE Power and Energy Society 2008 General Meeting: Conversion and Delivery of Electrical Energy in the 21st Century, PES, art. no. 4596680, 2008.

[42] L. Girardin, F. Maréchal, M. Dubuis, N. Calame-Darbellay, and D. Favrat, "EnerGis: A geographical information based system for the evaluation of integrated energy conversion systems in urban areas," Energy, vol. 35, pp. 830-840, 2010.

[43] R. Turton, R. Bailie, W. Whiting, and J. Shaiewitz, Analysis, synthesis and design of chemical processes. New Jersey, USA: Prentic Hall, 1998.

[44] G.-D. Ulrich, A guide to chemical engineering process design and economics. New York, USA: Wiley, 1996.

[45] OFEN, "Global energy Swiss statistics 2010," tech. rep., Swiss Federal Office of Energy, Bern, Switzerland, 2010.

[46] F. Maréchal and B. Kalitventzeff, "Targeting the minimum cost of energy requirements: A new graphical technique for evaluating the integration of utility systems," Computers \& Chemical Engineering, vol. 20, pp. S225-S230, 1996.

[47] OFEN, "Swiss electricity statistics 2010," tech. rep., Swiss Federal Office of Energy, Bern, Switzerland, 2010.

[48] M. Haring, "Deep heat mining: Development of a cogeneration power plant from an enhanced geothermal system in Basel, Switzerland," in Geothermal Resources Council Transactions, vol. 28, pp. 219-222, 2004. 
[49] E. Schill, P. Klinger, and K.-H. Schadle, "Increase of productivity in the Riehen geothermal system (System): Tracer and reservoir model," in Geophysical Research Abstracts, EGU General Assembly, 2011, art. no. 8142, vol. 13, 2011.

[50] S. Haehnlein, P. Bayer, and P. Blum, "International Legal Status of the Use of Shallow Geothermal Energy," Renewable and Sustainable Energy Reviews, vol. 14, pp. 2611-2625, 2010 .

\section{Appendix}

\section{A Details for geothermal resources models}

The conceptual flowsheets for the models of the EGS and of the aquifers are displayed in Figure 10 and 11. Assuming a sustainable exploitation, the temperature of the resource can be predicted

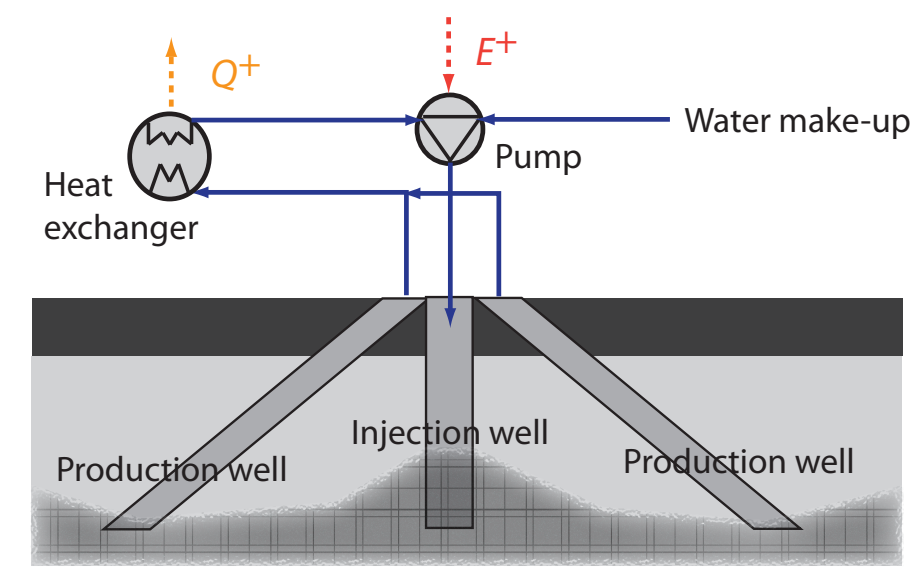

Figure 10: Conceptual flowsheet for the model of EGS

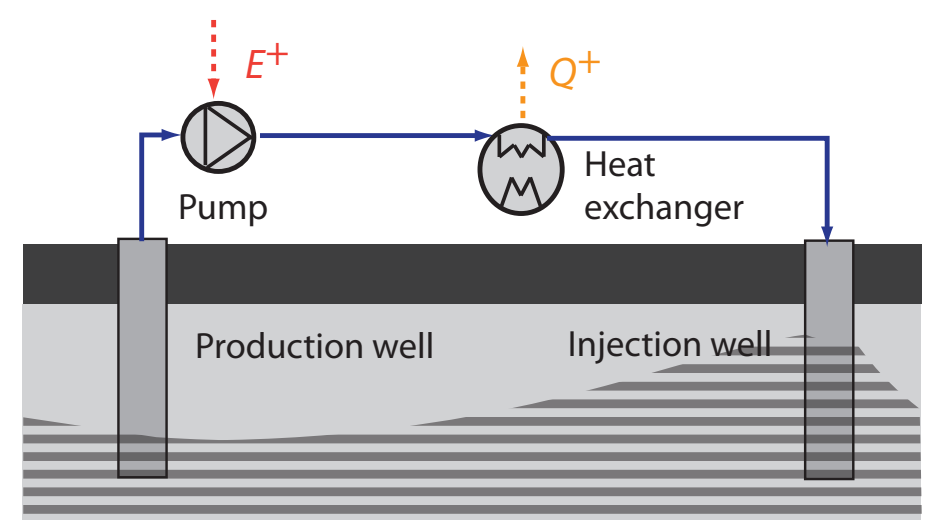

Figure 11: Conceptual flowsheet for the model of shallow and deep aquifers

in function of its depth $z$ in $m$ :

$$
T_{r, z}=T_{0}+\left(z-\frac{\theta}{2}\right) \cdot \frac{\Delta T}{\Delta z}
$$

where $T_{0}$ is the temperature at the surface, assumed to be $12^{\circ} C, \theta$ the aquifer thickness, extracted from the database for each potential resource, and $\frac{\Delta T}{\Delta z}$ the geothermal gradient. For the case study, the average gradient from the surface to the bedrock at $3000 \mathrm{~m}$ is $0.0345^{\circ} \mathrm{C} / \mathrm{m}$, for the 
profile extracted from the database. For HDR, no thickness is defined, and the temperature is just calculated in function of the depth and of the gradient. For the case study, data from the pilot EGS in Soultz-sous-Forêts (41), in France and from the projected EGS in Basel (48), in Switzerland are used, with a temperature of $200^{\circ} \mathrm{C}$ at $5000 \mathrm{~m}$, which gives a gradient of $0.038^{\circ} \mathrm{C} / \mathrm{m}$.

The thermal power available from the geothermal resource is calculated by:

$$
\dot{Q}_{r}^{+}=\dot{m}_{r} \cdot c_{p} \cdot\left(T_{r, \text { in }}-T_{r, \text { out }}\right)
$$

where $\dot{m}_{r}$, in $\mathrm{kg} / \mathrm{s}$ is the expected mass flow rate from the aquifer or the EGS, $c_{p}$ the specific heat from the geothermal water, in $\mathrm{kJ} / \mathrm{kg} / \mathrm{C}, T_{r, \text { in }}$ the temperature at well, and $T_{r, \text { out }}$ the reinjection temperature. For aquifers, $T_{r, i n}=T_{r, z}$ is assumed. For EGS, there is a temperature difference between the HDR and the water at well, calculated by:

$$
T_{r, i n}=T_{r, z}-\Delta T
$$

where $\Delta T$ is the temperature difference between HDR and water. In Soultz-sous-Forêts HDR temperature is $200^{\circ} \mathrm{C}$ and varies between $175^{\circ} \mathrm{C}$ and $185^{\circ} \mathrm{C}$ at well(41). Therefore, $\Delta T=20^{\circ} \mathrm{C}$ is assumed for EGS.

Because of the high geological uncertainties, the mass flow rate can not be known before the wells are drilled and is expressed as an expected flow rate, based on the resource type and on actual flow rates of existing systems. The 1500m aquifer of Riehen in Switzerland has an actual production of $18 \mathrm{~L} / \mathrm{s}$, and is planned to be increased to $23 \mathrm{~L} / \mathrm{s}$ (49). The technical report for the assessment of the geothermal potential for the region of Neuchâtel in Switzerland (36) expects a flow rate of $15-20 \mathrm{~L} / \mathrm{s}, 10-15 \mathrm{~L} / \mathrm{s}$ and $10-15 \mathrm{~L} / \mathrm{s}$ from three different aquifers $(350-560 \mathrm{~m}$, 750-1070m, 1500-1750m, respectively). In Soultz-sous-Forêts, the final mass flow rate from the EGS is expected between 70 and $100 \mathrm{~L} / \mathrm{s}$, but currently only $35 \mathrm{~L} / \mathrm{s}$ are used (41). For the case study, $20 \mathrm{~L} / \mathrm{s}$ is assumed for aquifers and $50 \mathrm{~L} / \mathrm{s}$ for EGS.

The reinjection temperature of geothermal water is limited for EGS, due to the geochemistry of the water. In the case of Soultz-sous-Forêts (41), this limit is $70^{\circ} \mathrm{C}$, which is taken as the lowest possible reinjection temperature for the EGS model. In (36), the reinjection temperatures assumed vary between 10 and $30^{\circ} \mathrm{C}$ for aquifers from 350 to $1750 \mathrm{~m}$. For shallow aquifers (less than $400 \mathrm{~m})$, limitation for reinjection in Switzerland is a temperature difference of $3^{\circ} \mathrm{C}(50)$.

The electrical power consumed by the pumps for the exploitation is calculated by:

$$
\dot{E}_{r}^{+}=\frac{\dot{m}_{r} \cdot d P}{\rho \cdot \epsilon_{p}}
$$

where $d P$ is the pressure difference of the pump, in $P a, \rho$ the density of geothermal water, in $\mathrm{kg} / \mathrm{m}^{3}$, and $\epsilon_{p}$ the total efficiency of the pump.

The costs associated with the drilling of the wells are calculated in function of the depth and of the type of resource. For EGS, the investment cost for resource exploitation in USD is calculated by an empirical non-linear correlation, extrapolated from the data given in (37), valid from $1500 \mathrm{~m}$ down to $10000 \mathrm{~m}$ :

$$
C_{\text {drill }, r}=n_{\text {wells }} \cdot\left(3 \cdot 10^{-8} \cdot z^{2}+0.0019 \cdot z-1.3958\right) \cdot 10^{6}
$$

where $n_{\text {wells }}$ is the number of wells required, and $z$ the resource depth in $\mathrm{m}$.

For aquifers, data are available in (35) and summarized in Table 5. They are used to interpolate the drilling costs of one well for an aquifer:

$$
C_{d r i l l, r}=n_{w e l l s} \cdot C_{d r i l l, w e l l}(z)
$$




\begin{tabular}{|l|l|}
\hline Depth $[m]$ & $\begin{array}{l}\text { Cost of a } \\
\text { well, in mio } \\
\text { USD }\end{array}$ \\
\hline 500 & 0.902 \\
1000 & 2.405 \\
1500 & 3.908 \\
2000 & 5.411 \\
2500 & 6.914 \\
\hline
\end{tabular}

Table 5: Data for drilling costs associated with the exploitation of aquifers, from (35)

\section{B Details for conversion technologies models}

Figures 12 to 16 show the conceptual flowsheets of the conversion technologies included in the superstructure. Table 6 shows the thermodynamic data of the working fluids of the ORC models.

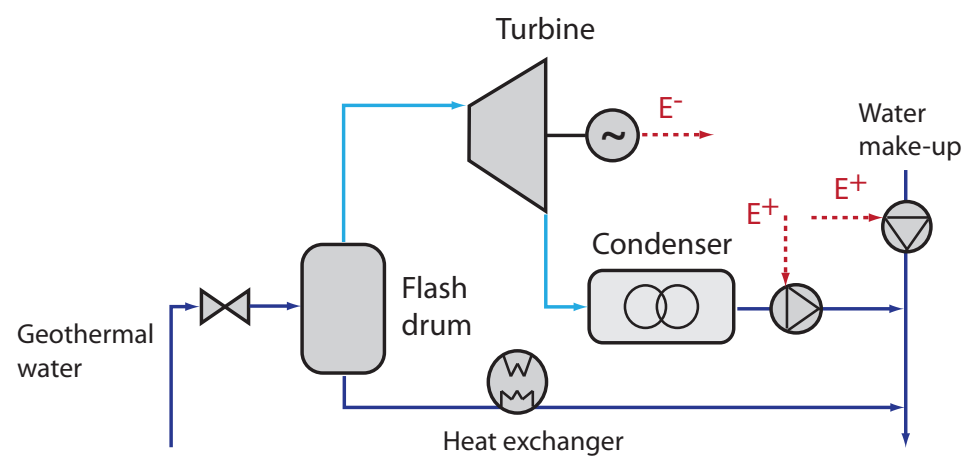

Figure 12: Conceptual flowsheet for the model of single-flash

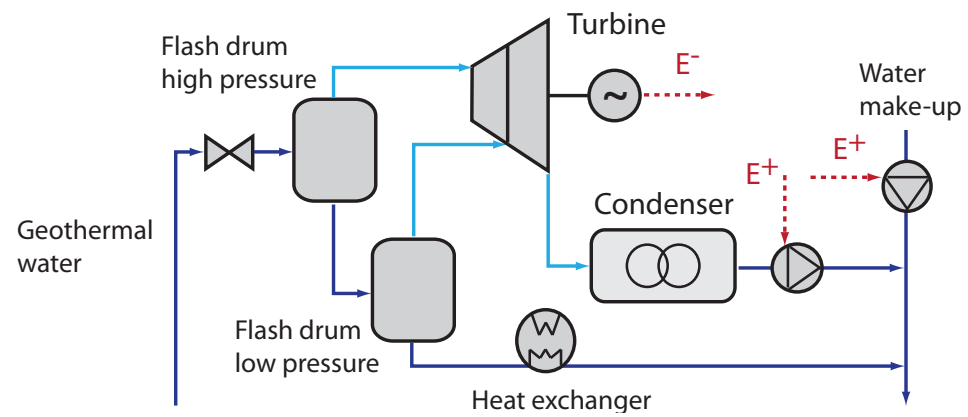

Figure 13: Conceptual flowsheet for the model of double-flash 


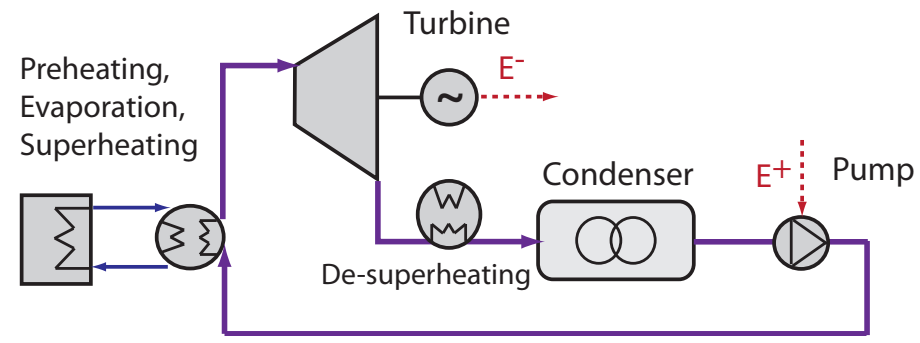

Figure 14: Conceptual flowsheet for the model of single-loop ORC

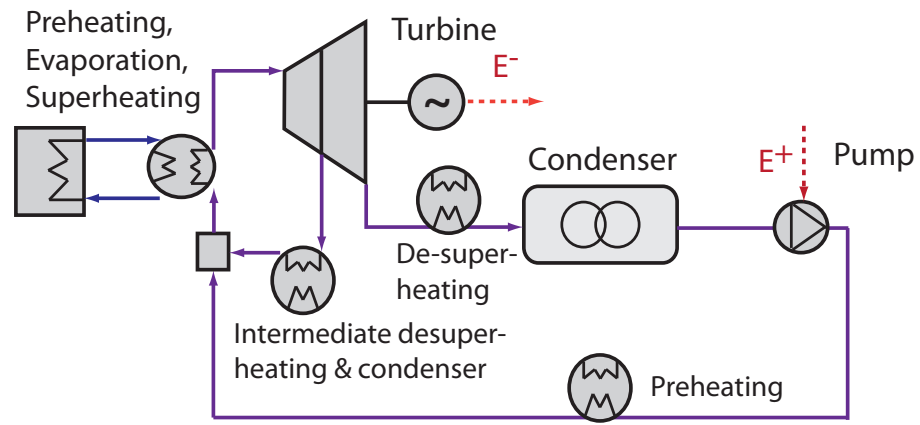

Figure 15: Conceptual flowsheet for the model of ORC with an intermediate draw-off

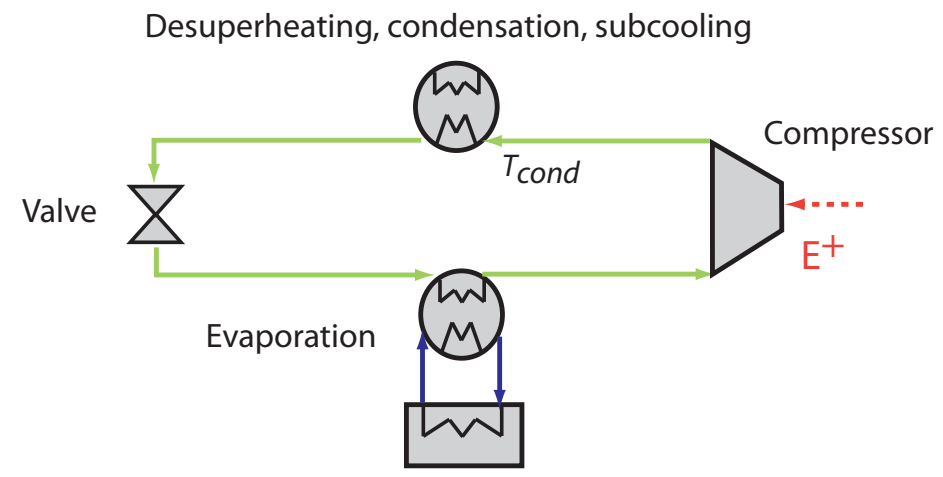

Figure 16: Conceptual flowsheet for the model of heat pump

\begin{tabular}{|l|l|l|l|l|}
\hline Fluid & $\begin{array}{l}\text { Molecular } \\
\text { Weight } \\
{[\mathrm{kg} / \mathrm{kmol}]}\end{array}$ & $\begin{array}{l}\text { Critical } \\
\text { tempera- } \\
\left.\text { ture [ }{ }^{\circ} \mathrm{C}\right]\end{array}$ & $\begin{array}{l}\text { Critical } \\
\text { pressure } \\
{[\text { bar }]}\end{array}$ & $\begin{array}{l}\text { Boiling } \\
\text { tempera- } \\
\left.\text { ture [ }{ }^{\circ} \mathrm{C}\right]\end{array}$ \\
\hline n-pentane & 72.151 & 196.63 & 33.75 & 36.05 \\
cyclo-butane & 56.108 & 186.85 & 49.85 & 12.51 \\
iso-butane & 58.124 & 134.98 & 36.48 & -11.83 \\
iso-pentane & 72.151 & 187.25 & 33.34 & 27.85 \\
benzene & 78.114 & 288.95 & 49.24 & 80.15 \\
toluene & 92.141 & 318.85 & 42.15 & 110.65 \\
n-butane & 58.124 & 152.01 & 37.97 & -0.48 \\
R134a & 102.032 & 101.06 & 40.59 & -26.07 \\
\hline
\end{tabular}

Table 6: Characteristics of the different potential working fluids included in the models of ORCs and heat pump (taken from Belsim database) 